Supporting Information

\title{
Crossover Studies of Methyl Migration from Oxygen to Iron in the Iron-Manganese Methoxycarbyne Complex $\mathrm{Cp}(\mathrm{CO}) \mathrm{Fe}(\square-\mathrm{COCH})(\square-\mathrm{CO}) \mathrm{Mn}(\mathrm{CO}) \mathrm{MeCp}$
}

\author{
William H. Hersh* and Raymond H. Fong ${ }^{\dagger}$
}

Department of Chemistry and Biochemistry, Queens College and the Graduate Center of the City University of New York, Flushing, New York, 11367-1597, and Department of Chemistry and Biochemistry, University of California, Los Angeles, California 90024

william_hersh@qc.edu

Table of Contents

\begin{tabular}{|l|l|}
\hline S1-3 & Table S-1. Kinetics Data for Methoxycarbyne Decomposition. \\
\hline S3 & Table S-2. Observed and Calculated Product Yields as a Function of $\left[\mathrm{PPh}_{3}\right]$. \\
\hline S3-6 & Additional Control Experiments; Table S-3 (page S4) \\
\hline S6-10 & Kinetic Details of the CpFe(CO)Me Mechanism; Table S-4 (page S10) \\
\hline S8 & Chart S-1. Reaction Steps for Scheme S-3 \\
\hline S11 & Chart S-2. Differential Equations for Scheme S-3 \\
\hline S11 & Chart S-2. Differential Equations for Scheme 6 \\
\hline S12-31 & Fortran Program CRK2005 \\
\hline
\end{tabular}

\begin{tabular}{|c|c|c|c|c|c|c|c|c|}
\hline \multicolumn{9}{|c|}{ Table S-1. Kinetics Data for Methoxycarbyne Decomposition } \\
\hline \multirow{2}{*}{\multicolumn{9}{|c|}{ 1. $75^{\circ} \mathrm{C}$ reactions at different $\mathrm{PPh} 3$ concentrations }} \\
\hline & & & & & & & & \\
\hline $\begin{array}{ll}\text { Run } 1 \\
\end{array}$ & & & Run 2 & & & Run 3 & & \\
\hline [PPh3] (M) & $\mathrm{t}(\mathrm{sec})$ & $1 a(M)$ & $\begin{array}{r}\text { PPh3] } \\
(\mathrm{M})\end{array}$ & $\mathrm{t}(\mathrm{sec})$ & 1a (M) & $\begin{array}{r}\text { PPh3] } \\
(\mathrm{M})\end{array}$ & $\mathrm{t}(\mathrm{sec})$ & 1a (M) \\
\hline \multirow[t]{16}{*}{0.00} & 0 & 0.0280 & 0.0577 & 0 & 0.0104 & 0.128 & 0 & 0.0254 \\
\hline & 6900 & 0.0165 & & 901 & 0.0089 & & 899 & 0.0206 \\
\hline & 8820 & 0.0120 & & 1573 & 0.0084 & & 1799 & 0.0176 \\
\hline & 10020 & 0.0107 & & 2462 & 0.0076 & & 2702 & 0.0148 \\
\hline & 11220 & 0.0099 & & 3362 & 0.0068 & & 3602 & 0.0137 \\
\hline & 12420 & 0.0082 & & 4562 & 0.0056 & & 4325 & 0.0122 \\
\hline & 13620 & 0.0077 & & 5761 & 0.0051 & & 5104 & 0.0113 \\
\hline & 14820 & 0.0072 & & 6961 & 0.0039 & & 6001 & 0.0092 \\
\hline & 16020 & 0.0068 & & 7860 & 0.0038 & & 6903 & 0.0085 \\
\hline & 17220 & 0.0055 & & 8760 & 0.0035 & & 7621 & 0.0063 \\
\hline & 18420 & 0.0049 & & 9960 & 0.0030 & & 8406 & 0.0070 \\
\hline & 19620 & 0.0044 & & 11160 & 0.0022 & & 9127 & 0.0065 \\
\hline & 20822 & 0.0041 & & 12360 & 0.0022 & & 9846 & 0.0055 \\
\hline & 22020 & 0.0037 & & 13890 & 0.0021 & & 10567 & 0.0045 \\
\hline & & & & 15060 & 0.0018 & & 11228 & 0.0038 \\
\hline & & & & 16260 & 0.0012 & & 12067 & 0.0035 \\
\hline
\end{tabular}




\begin{tabular}{|r|r|r|l|r|r|r|l|l|l|l|}
\hline Run 4 & & & Run 5 & & & & & & \\
\hline [PPh3] (M) & $\mathrm{t}(\mathrm{sec})$ & $\mathbf{1 a}$ (M) & & $\begin{array}{r}\text { PPh3] } \\
\text { (M) }\end{array}$ & $\mathrm{t}(\mathrm{sec})$ & $\mathbf{1 a}$ (M) & & & & \\
\hline 0.422 & 0 & 0.0205 & & 0.800 & 0 & 0.0318 & & & & \\
\hline & 901 & 0.0167 & & & 600 & 0.0251 & & & & \\
\hline & 2102 & 0.0094 & & & 1140 & 0.0188 & & & & \\
\hline & 3243 & 0.0078 & & & 1680 & 0.0149 & & & & \\
\hline & 4081 & 0.0056 & & & 2101 & 0.0133 & & & & \\
\hline & 4982 & 0.0044 & & & 2640 & 0.0102 & & & & \\
\hline & 5882 & 0.0036 & & & 3060 & 0.0087 & & & & \\
\hline & 7082 & 0.0021 & & & 3600 & 0.0068 & & & & \\
\hline & & & & & 4020 & 0.0050 & & & & \\
\hline & & & & & 4381 & 0.0038 & & & & \\
\hline
\end{tabular}

\section{Carbyne Crossover}

\begin{tabular}{|c|c|c|c|c|c|c|c|c|}
\hline Run 6 & & & & & & & & \\
\hline [PPh3] (M) & $t(\sec )$ & $1 \mathbf{a}$ & 1bd3 & $2 \mathbf{a}$ & $2 \mathbf{2 b}$ & $2 a+2 a d 3$ & $2 b+2 b d 3$ & $\operatorname{MeCpMn(CO)}$ \\
\hline \multirow[t]{2}{*}{0.11591} & 0 & 0.022443 & 0.021981 & 0.000000 & 0.000000 & 0.000000 & 0.000000 & 0.000000 \\
\hline & 1800 & 0.021185 & 0.021019 & 0.000168 & 0.000146 & 0.000597 & 0.000971 & 0.001545 \\
\hline $\bar{Q}=$ & 3480 & 0.019496 & 0.019772 & 0.000711 & 0.000585 & 0.000997 & 0.001347 & 0.002888 \\
\hline \multirow[t]{12}{*}{$6.32592 \mathrm{E}-04$} & 5400 & 0.015886 & 0.017325 & 0.000827 & 0.000811 & 0.001432 & 0.001881 & 0.004215 \\
\hline & 7260 & 0.014567 & 0.016396 & 0.001159 & 0.001249 & 0.001701 & 0.002310 & 0.005872 \\
\hline & 10740 & 0.012812 & 0.014875 & 0.001890 & 0.001890 & 0.003989 & 0.004842 & 0.008381 \\
\hline & 14760 & 0.010405 & 0.012872 & 0.001834 & 0.002007 & 0.004476 & 0.006044 & 0.010662 \\
\hline & 22800 & 0.007222 & 0.010295 & 0.002843 & 0.003597 & 0.005714 & 0.007644 & 0.014724 \\
\hline & 29640 & 0.005488 & 0.008430 & 0.003049 & 0.003788 & 0.007097 & 0.009425 & 0.017297 \\
\hline & 37440 & 0.003404 & 0.006634 & 0.003903 & 0.005039 & 0.007408 & 0.010629 & 0.020235 \\
\hline & 45780 & 0.002548 & 0.005072 & 0.003881 & 0.005271 & 0.007761 & 0.011730 & 0.022978 \\
\hline & $\%$ yield & & & $19.51 \%$ & $31.17 \%$ & $39.01 \%$ & $69.37 \%$ & $62.43 \%$ \\
\hline & Rate $=$ & $4.80 \mathrm{E}-05$ & \pm & $1.03 \mathrm{E}-06$ & & & & \\
\hline & & & $3.159 \mathrm{E}-05$ & \pm & $6.36 \mathrm{E}-07$ & & & \\
\hline & & & & & & & & \\
\hline \multicolumn{4}{|c|}{ ssover - low [1bd3] } & & & & & \\
\hline
\end{tabular}

\section{Run 9}

\begin{tabular}{|r|r|r|r|r|r|r|r|}
\hline [PPh3] (M) & $\mathrm{t}(\mathrm{sec})$ & $\mathbf{1 a}$ & $\mathbf{2 a}$ & $\mathbf{2 b}$ & $\mathbf{2 a + 2 a d 3}$ & $\mathbf{2 b + 2 b d 3}$ & \multicolumn{2}{|c|}{ MeCpMn(CO)3 } \\
\hline 0.12378 & 0 & 0.026153 & 0.000000 & 0.000000 & 0.000000 & 0.028455 & 0.000000 \\
\hline & 1800 & 0.023601 & 0.001238 & 0.000236 & 0.001967 & 0.028455 & 0.001883 \\
\hline \hline$=$ & 3720 & 0.020076 & 0.001553 & 0.000642 & 0.003943 & 0.028455 & 0.003226 \\
\hline $9.59392 \mathrm{E}-04$ & 5580 & 0.017573 & 0.002189 & 0.001236 & 0.004704 & 0.028455 & 0.004586 \\
\hline & 7860 & 0.016455 & 0.002682 & 0.001650 & 0.005485 & 0.028455 & 0.006094 \\
\hline & 11100 & 0.013408 & 0.003169 & 0.002749 & 0.006399 & 0.028455 & 0.007618 \\
\hline & 14820 & 0.011427 & 0.004278 & 0.003436 & 0.008966 & 0.028455 & 0.010255 \\
\hline & 21840 & 0.007706 & 0.005954 & 0.005328 & 0.010928 & 0.028455 & 0.012609 \\
\hline & 28860 & 0.004897 & 0.006530 & 0.006414 & 0.013356 & 0.028455 & 0.014395 \\
\hline & 34620 & 0.002909 & 0.007535 & 0.007218 & 0.013131 & 0.028455 & 0.014959 \\
\hline & 41820 & 0.001079 & 0.007551 & 0.008390 & 0.015209 & 0.028455 & 0.016719 \\
\hline & $\%$ yield & & $30.11 \%$ & $33.46 \%$ & $60.66 \%$ & & $66.68 \%$ \\
\hline & Rate $=$ & $6.88 \mathrm{E}-05$ & \pm & $4.04 \mathrm{E}-06$ & & & \\
\hline
\end{tabular}




\begin{tabular}{|c|c|c|c|c|c|c|c|}
\hline \multicolumn{4}{|c|}{ 4. Control Crossover - high [1bd3] } & & & & \\
\hline \multicolumn{8}{|c|}{\begin{tabular}{|l|l} 
Run 10 & \\
\end{tabular}} \\
\hline [PPh3] (M) & $\mathrm{t}(\mathrm{sec})$ & $1 \mathbf{a}$ & $2 a$ & 2b & $2 a+2 a d 3$ & $2 b+2 b d 3$ & $\operatorname{MeCpMn(CO)}$ \\
\hline \multirow[t]{2}{*}{0.16165} & 0 & 0.025708 & 0.000000 & 0.000000 & 0.000000 & 0.063199 & 0.000000 \\
\hline & 360 & 0.025417 & 0.000000 & 0.000000 & 0.000000 & 0.063199 & 0.000528 \\
\hline$\square=$ & 2520 & 0.019897 & 0.000953 & 0.000477 & 0.003789 & 0.063199 & 0.002914 \\
\hline \multirow[t]{7}{*}{0.001495537} & 5640 & 0.017713 & 0.002657 & 0.001571 & 0.009171 & 0.063199 & 0.005611 \\
\hline & 9420 & 0.011893 & 0.003302 & 0.001735 & 0.009235 & 0.063199 & 0.009150 \\
\hline & 15240 & 0.006821 & 0.004198 & 0.003148 & 0.012774 & 0.063199 & 0.011385 \\
\hline & 21540 & 0.004014 & 0.004767 & 0.004014 & 0.015076 & 0.063199 & 0.012931 \\
\hline & 29460 & 0.002905 & 0.005305 & 0.004598 & 0.017000 & 0.063199 & 0.013204 \\
\hline & \% yield & & $23.27 \%$ & $20.16 \%$ & $74.55 \%$ & & $57.91 \%$ \\
\hline & Rate $=$ & $7.84 \mathrm{E}-05$ & \pm & $3.76 \mathrm{E}-06$ & & & \\
\hline
\end{tabular}

Table S-2. Observed and Calculated Product Yields as a Function of $\left[\mathrm{PPh}_{3}\right] .{ }^{a}$

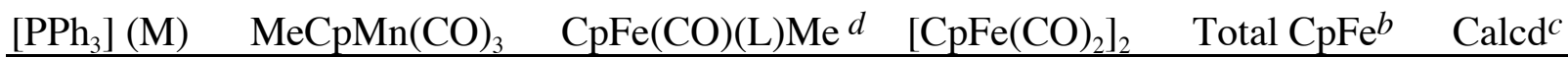

\begin{tabular}{lccccc}
0.00 & 91 & $11^{d}$ & 16 & $65^{e}$ & 100 \\
0.057780 & 80 & 48 & 10 & 58 & 78 \\
0.128 & 71 & 48 & 10 & 58 & 62 \\
0.442 & 38 & 19 & 7 & 26 & 32 \\
0.800 & $45^{f}$ & 14 & 2 & 16 & 21 \\
\hline
\end{tabular}

a All data taken at the conclusion of kinetic runs $1-5$ in Table 1 , for $1 \mathrm{a}$ at $75^{\circ} \mathrm{C}$ in $\mathrm{C}_{6} \mathrm{D}_{6}$. Yields for the $\mathrm{CpFe}$ compounds are on the basis of the $\mathrm{CpFe}$ unit, not moles of the (dimeric and tetrameric) products. ${ }^{b}$ Total yield of CpFe products. ${ }^{c}$ from eq 1 , calcd yield of $\mathrm{CpFe}$ or $\mathrm{MeCpMn}=k_{1} /\left(k_{1}+\right.$ $\left.k_{2}\left[\mathrm{PPh}_{3}\right]\right) . d_{\mathrm{L}}=\mathrm{CO}$ for the $\left[\mathrm{PPh}_{3}\right]=0$ run, and $\mathrm{L}=\mathrm{PPh}_{3}$ for the others. $e[\mathrm{CpFe}(\mathrm{CO})]_{4}$ formed in $38 \%$

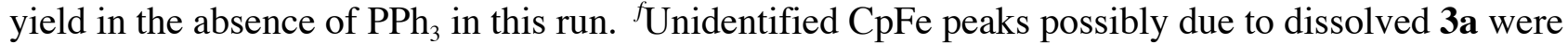
present and the associated $\mathrm{MeCp}$ peaks may overlap with $\mathrm{MeCpMn}(\mathrm{CO})_{3}$, giving the high value.

Additional Control Experiments. The experiments described in eq 2-3 were confirmed by results from further control experiments in runs S1-S5 (Table S-3).

Anion control experiments are shown in Scheme S-1. Reaction of the isolable anion $\mathbf{3 b}$ $\mathbf{C H}_{3} \mathbf{P P h}_{3}{ }^{+}$, which forms via demethylation of $\mathbf{1 b}$ by $\mathrm{PPh}_{3}$, and carbyne $\mathbf{1 a}$ (Table S-3, run S-1) gave no crossover; only $\mathbf{2 a}$ was observed. There is a problem with this experiment, however, in that we have no evidence of the solubility in benzene of the independently synthesized anion. That is, a small Cp signal was seen at $\square 4.77$ in all decomposition reactions of 1a in which $\mathrm{PPh}_{3}$ was present (and only in those reactions), and integration of this signal was consistent with assignment to the $\mathrm{Cp}$ resonance of the anion. Supersaturated solutions apparently form, since at variable points during the decomposition of 1a, large amounts of precipitate would suddenly 
Table S-3. Summary of Additional Experimental Data: Rate Constants for Carbyne Decomposition and Carbyne and Product Crossover Results. ${ }^{a}$

\begin{tabular}{|c|c|c|c|c|c|}
\hline run & $\begin{array}{l}{[\mathbf{1 a}]} \\
(\mathrm{M})\end{array}$ & $\begin{array}{l}{\left[\mathrm{PPh}_{3}\right]} \\
\text { (M) }\end{array}$ & Additive (M) & $10^{4} k\left(\mathrm{~s}^{-1}\right)^{a}$ & crossover $^{b}$ \\
\hline S-1 & 0.038 & 0.10 & $\begin{array}{l}\mathbf{3 b}-\mathbf{C H}_{3} \mathbf{P P h}_{3}{ }^{+\cdot} \\
\mathbf{C H}_{2} \mathbf{C l}_{2}(0.016)\end{array}$ & & $\begin{array}{l}\text { no }\left(5 \mathrm{~h} \text { in } \mathrm{C}_{6} \mathrm{H}_{6}, \text { no } \mathbf{2 b} \text { observed; }\right. \\
<18 \% \text { exchange })^{c}\end{array}$ \\
\hline S-2 & & 0.10 & $\begin{array}{l}\mathbf{1 b}-d_{3}(0.018) \\
\text { 3a-Na+ }(0.02) \\
\mathrm{CH}_{3} \mathrm{PPh}_{3}{ }^{+} \mathrm{Br}^{-}(0.02)\end{array}$ & $\begin{array}{l}\text { 1b- } d_{3}: \\
0.93 \pm 0.03\end{array}$ & $\begin{array}{l}\text { no (no } \mathbf{2 b} \text { (or } \mathbf{2 a} \text { ) observed during } \\
9 \mathrm{~h}, \sim 96 \% \text { conversion of } \mathbf{1 b}-d_{3} \text { ) }\end{array}$ \\
\hline S-3 & 0.016 & 0.095 & $\begin{array}{l}\mathbf{1 b}-d_{3}(0.018) \\
\text { 3a-Na+ }(0.005) \\
\mathrm{CH}_{3} \mathrm{PPh}_{3}{ }^{+} \mathrm{Br}^{-}(0.01)\end{array}$ & $\begin{array}{l}0.44 \pm 0.02 \quad \mathbf{~ 1 b}- \\
d_{3}:\end{array}$ & $\begin{array}{l}\text { yes }(\sim 100 \% \text { after } 3 \mathrm{~h}, \sim 42 \% \text { and } \\
\sim 28 \% \text { conversions of } \mathbf{1 a} \text { and } \mathbf{1 b}-d_{3} \text {; } \\
\mathrm{N}_{2} \text { atmosphere) }\end{array}$ \\
\hline S-4 & & 0.10 & 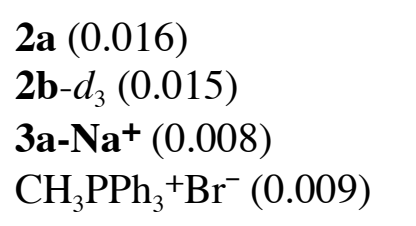 & & $\begin{array}{l}\text { no }\left(8 \mathrm{~h} \text { under } \mathrm{N}_{2} \text { atmosphere, } 1.7 \mathrm{~h}\right. \\
\text { under vacuum; } \mathrm{CpFe}(\mathrm{CO})\left(\mathrm{PPh}_{3}\right) \mathrm{H} \text {, } \\
\sim 10 \% \text { of } \mathbf{2 a} \text {, observed after } 3 \mathrm{~h})\end{array}$ \\
\hline S-5 & & 0.083 & $\begin{array}{l}\mathbf{2 a}(0.057) \\
\mathbf{2 b}-d_{3}(0.028) \\
\mathrm{MeCpMn}(\mathrm{CO})_{3}(0.028)\end{array}$ & & $\begin{array}{l}\text { no }\left(5.5 \mathrm{~h}, \mathrm{~N}_{2} \text { atmosphere; no }\right. \\
\text { further change after additional } 4.5 \\
\text { h with } 0.002 \mathrm{M} \text { 3a-C } \mathbf{C H}_{\mathbf{3}} \mathbf{P P h}_{3}{ }^{+} \cdot \\
\left.\mathbf{C H}_{\mathbf{2}} \mathbf{C l}_{\mathbf{2}} \text { added }\right)\end{array}$ \\
\hline
\end{tabular}

${ }^{a}$ All data collected in $\mathrm{C}_{6} \mathrm{D}_{6}$ solvent except for run S-1 where the solvent was $\mathrm{C}_{6} \mathrm{H}_{6}$, at $65^{\circ} \mathrm{C}$. Except as noted, rate constants are for decomposition of 1a. See Experimental Section, ${ }^{1} \mathrm{H}$ NMR Reactions, for general methods. For runs S-1 $-\mathrm{S}-5$ the $\mathrm{C}_{6} \mathrm{D}_{6}\left(\mathrm{C}_{6} \mathrm{H}_{6}\right.$ for run S-1; see below) was added in the glove box, and runs S-1 and S-3 $-\mathrm{S}-5$ were carried out in heavy-walled tubes sealed with a vacuum stopcock, because the anion usually caused cracking of the NMR tubes during freezing; only run S-2 with 3a- $\mathbf{N a}^{+}$was successfully carried out in an NMR tube. Runs S-1 and S-2 were carried out under vacuum, and S-3 - S-5 under nitrogen. The reaction of $\mathbf{1 a}$ and $\mathbf{3 b}$ (run S-1) was carried out in $\mathrm{C}_{6} \mathrm{H}_{6}$ in a vacuum-stopcock sealed vessel (under vacuum) rather than in an NMR tube, since $\mathbf{3 b}$ is nearly insoluble in benzene. The solvent was removed on a vacuum pump after the reaction was done, and the residue taken up in $\mathrm{C}_{6} \mathrm{D}_{6}$ for NMR analysis; no $\mathbf{2 b}$ was observed, and the upper limit of exchange was calculated on the basis of $\square_{1}: \square_{3}>17.5: 1$. ${ }^{b}$ Crossover of alkyl label between $2 \mathbf{a}$ and $\mathbf{2 b}$. Complete crossover is $100 \%$ exchange (see Experimental Section).

form with a concomitant decrease in the size of the $\square 4.77$ signal. In order to isolate the $\mathrm{CH}_{3} \mathrm{PPh}_{3}{ }^{+}$salt, recrystallization from methylene chloride was necessary, and a solvent molecule of crystallization is present. Heating the isolated salt $\mathbf{3 a}-\mathbf{C H}_{3} \mathbf{P P h} \mathbf{3}^{+} \cdot \mathbf{C H}_{2} \mathbf{C l}_{2}$ in $\mathrm{C}_{6} \mathrm{D}_{6}$ at $65^{\circ} \mathrm{C}$ imparted no color to the solution, nor any NMR signals attributable to the anion. Hence it is appears that the analytically pure crystalline material is insoluble in $\mathrm{C}_{6} \mathrm{D}_{6}$. 
An alternative way in which to carry out this type of control experiment lay in in-situ formation of the $\mathrm{CH}_{3} \mathrm{PPh}_{3}{ }^{+}$salt in benzene from the $\mathrm{Na}^{+}$salt of the anion and $\mathrm{CH}_{3} \mathrm{PPh}_{3}{ }^{+} \mathrm{Br}^{-}$. This resulted in observation of the $\square 4.77$ signal, and so was considered a better test of the anionmediated exchange hypothesis. Two experiments were carried out, both containing 1b- $d_{3}, \mathbf{3 a -}$ $\mathbf{N a}^{+}$, and $\mathrm{CH}_{3} \mathrm{PPh}_{3}{ }^{+} \mathrm{Br}^{-}$, and one also containing $\mathbf{1 a}$ (Scheme S-1). In the absence of $\mathbf{1 a}$ (run S-2, Table S-3), no methyl exchange - that is, no $\mathbf{2 a}$ or $\mathbf{2 b}$ - was observed even after $9 \mathrm{~h}$, at which point $96 \%$ decomposition of the carbyne would have taken place. In order to be certain that these new (and largely insoluble) additives were not somehow inhibiting methyl exchange, the control experiment was carried out in the presence of 1 a (run S-3, Table S-3), and methyl exchange was observed as before.

\section{Scheme S-1. Anion Control Experiments}
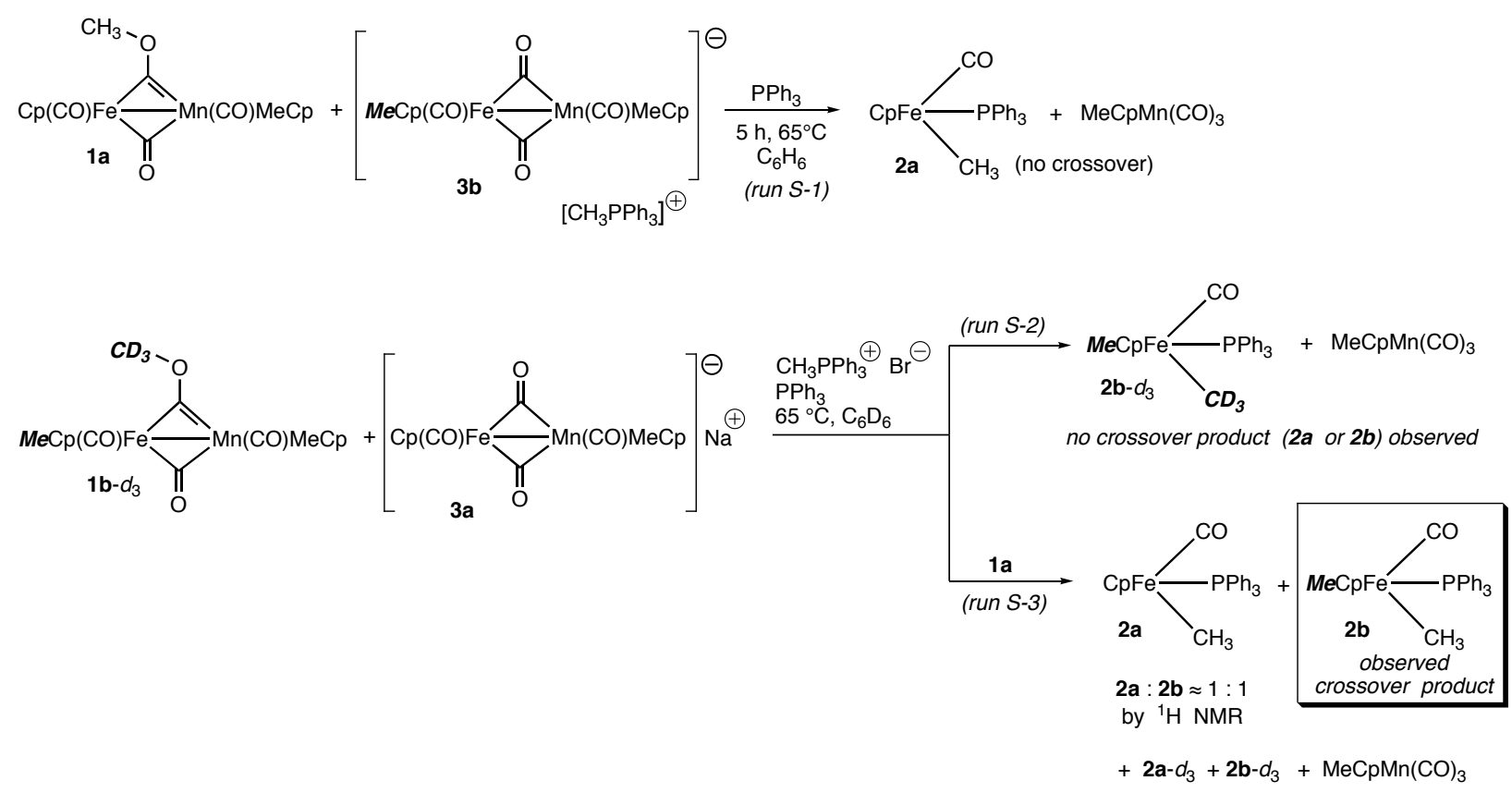

Product crossover control experiments are shown in Scheme S-2. Since both $\mathrm{MeCpMn}(\mathrm{CO})_{3}$ and anion 3 form during carbyne decomposition and so are present when methyl exchange occurs, two control experiments were carried out to test their involvement in the observed product crossover. In one experiment, the mononuclear alkyls were heated in the presence of the anion generated from $3-\mathrm{Na}^{+}$and $\mathrm{CH}_{3} \mathrm{PPh}_{3}{ }^{+} \mathrm{Br}^{-}$as described previously in Scheme S-1 (run S-4, Scheme S-2), and in the second experiment the alkyls were heated in the presence of $\mathrm{MeCpMn}(\mathrm{CO})_{3}$ (run S-5, Scheme S-2). No methyl exchange was detected. Further addition of $\mathbf{3 a}-\mathbf{C H}_{3} \mathbf{P P h}_{3}{ }^{+} \cdot \mathbf{C H}_{2} \mathbf{C l}_{2}$ to the $\mathrm{MeCpMn}(\mathrm{CO})_{3}$ reaction had no effect, either (run S-5, Scheme S-2). Since prolonged reaction of $\mathbf{2 a}$ and $\mathbf{2} \mathbf{b}-d_{3}$ gave slow methyl exchange, slow formation of some reactive intermediate might account for exchange. After $96 \mathrm{~h}$ at $80{ }^{\circ} \mathrm{C}$, at which point methyl exchange was $\sim 7 \%$ complete, $\sim 1 \mathrm{~mol} \%$ of $\mathrm{CpFe}(\mathrm{CO})\left(\mathrm{PPh}_{3}\right) \mathrm{H}$ was detected; its concentration remained fairly constant through $285 \mathrm{~h}$ at $80{ }^{\circ} \mathrm{C}$, at which point methyl exchange was $\sim 51 \%$ complete. $\mathrm{MeCpFe}(\mathrm{CO})\left(\mathrm{PPh}_{3}\right) \mathrm{H}$ was also detected in the hydride region of the NMR spectrum, and the relative ratios were comparable to the protio-alkyls $\mathbf{2 a}$ and $\mathbf{2 b}$. While these hydrides therefore might be candidates for inducing methyl crossover during carbyne 
Scheme S-2. Product Crossover Experiments

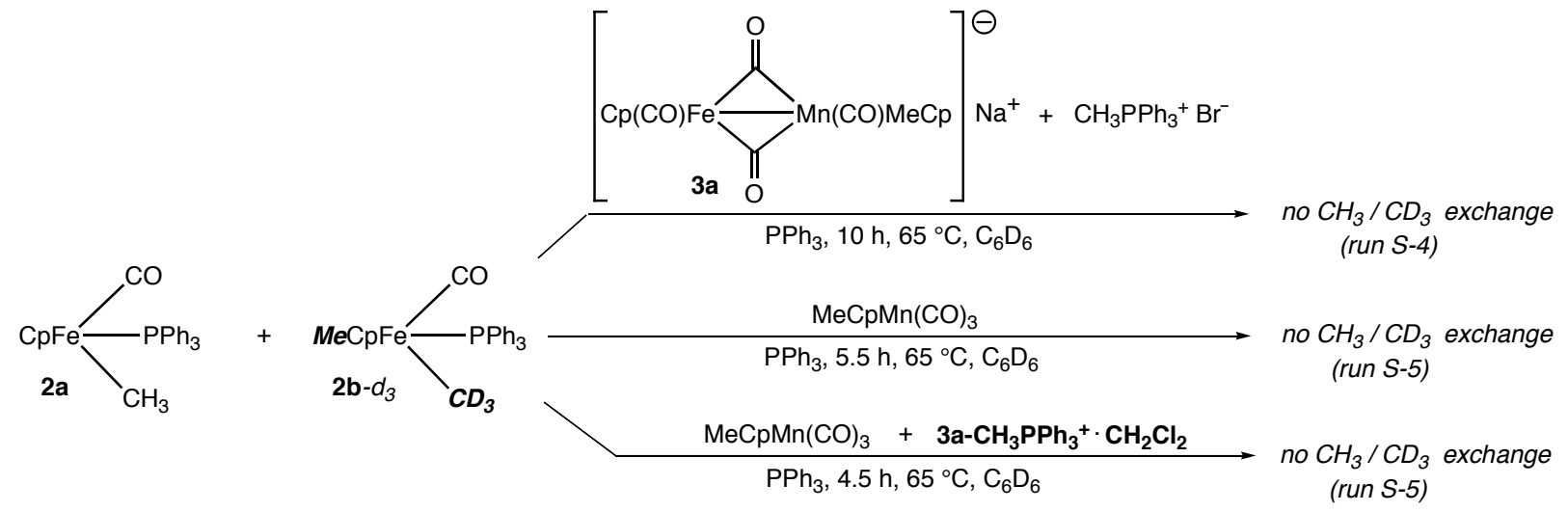

decomposition, it is extremely unlikely because they were never observed $(<\sim 1 \mathrm{~mol} \%$ of the $\mathrm{FeCH}_{3}$ products) in any crossover experiment before carbyne decomposition was complete, and in run $\mathrm{S}-4,10 \mathrm{~mol} \%$ of $\mathrm{CpFe}(\mathrm{CO})\left(\mathrm{PPh}_{3}\right) \mathrm{H}$ was found to be present (relative to 2a) after $3 \mathrm{~h}$ reaction at $65^{\circ} \mathrm{C}$, but while peaks due to this hydride continued to increase with further heating, no methyl exchange nor $\mathrm{MeCpFe}(\mathrm{CO})\left(\mathrm{PPh}_{3}\right) \mathrm{H}$ was observed.

Kinetic Details of the $\mathrm{CpFe}(\mathrm{CO}) \mathrm{Me}$ Mechanism. A mechanism involving the iron alkyl intermediate is shown in Scheme S-3. Starting from 1a, rate determining loss of $\mathrm{MeCpMn}(\mathrm{CO})_{3}$ would yield the 16-electron intermediate, $\mathrm{CpFe}(\mathrm{CO}) \mathrm{CH}_{3}(\mathbf{I a})$. Methyl exchange in the carbyne crossover experiment could then occur via interaction with the doubly-labeled saturated species $\mathbf{2} \mathbf{b}-d_{3}$, formed from $\mathbf{1 b}-d_{3}$ via decomposition to its 16-electron intermediate $\mathrm{MeCpFe}(\mathrm{CO}) \mathrm{CD}_{3}\left(\mathbf{I b}-d_{3}\right)$ followed by trapping with $\mathrm{PPh}_{3}$, or in the control crossover experiment by direct introduction of $\mathbf{2} \mathbf{b}-d_{3}$. Interaction of $\mathbf{I a}$ and $\mathbf{2} \mathbf{b}-d_{3}$ could give a methyl-bridged intermediate, which upon cleavage in the direction opposite to that in which it formed would give rise to methyl exchange. Crossover product $\mathbf{2 b}$ would be formed directly, leaving the 16electron intermediate $\mathrm{CpFe}(\mathrm{CO}) \mathrm{CD}_{3}\left(\mathbf{I a}-d_{3}\right)$ as the new chain-carrying species. Trapping of this species by $\mathbf{2 a}$ to give a new methyl-bridged intermediate followed again by cleavage in the opposite direction would give the other crossover product $\mathbf{2 a}-d_{3}$ and regenerate the initial catalyst, $\mathrm{CpFe}(\mathrm{CO}) \mathrm{CH}_{3}$. The mechanism would account for the crossover seen from carbynes 1a and $\mathbf{1 b}-d_{3}$ by introducing a catalytic reaction channel that results in methyl exchange after carbyne decomposition; that is, rate-determining formation of $\mathrm{CpFe}(\mathrm{CO}) \mathrm{CH}_{3}$ and $\mathrm{MeCpFe}(\mathrm{CO}) \mathrm{CD}_{3}$ results in catalytic scrambling of the methyl labels in the products already formed. The mechanism similarly would account for the "control crossover" experiment, where only the Cp carbyne 1a and the "other" product, the MeCp iron alkyl $\mathbf{2 b}-d_{3}$ are present, but exchange occurs in the same manner as seen starting with $\mathbf{1 a}$ and $\mathbf{1 b}-d_{3}$ since only one carbyne is necessary to enter into the catalytic exchange cycle as shown.

There are two major problems with the mechanism in Scheme S-3. One is the completely non-intuitive requirement that the 16-electron intermediate be trapped by iron alkyls $\mathbf{2 a}$ and $\mathbf{2 b}$ $d_{3}$ at a rate that is comparable to trapping by free $\mathrm{PPh}_{3}-$ that is, $k_{5}$ and $k_{6}$ must be comparable. As described in the paper, a lower limit of $k_{5}=3 \square 10^{3} \mathrm{M}^{-1} \mathrm{~s}^{-1}$ has been estimated by Wrighton, ${ }^{1}$ and Ford has found the rate of trapping by $\mathrm{CO}$ to be $3 \square 10^{6} \mathrm{M}^{-1} \mathrm{~s}^{-1}$ in THF, and suggested that the 16-electron intermediate is the solvento complex. ${ }^{2}$ Such high rates of reaction for trapping 


\section{Scheme S-3. A Methyl Exchange Mechanism Catalyzed by $\mathrm{CpFe}(\mathrm{CO}) \mathrm{Me}$}

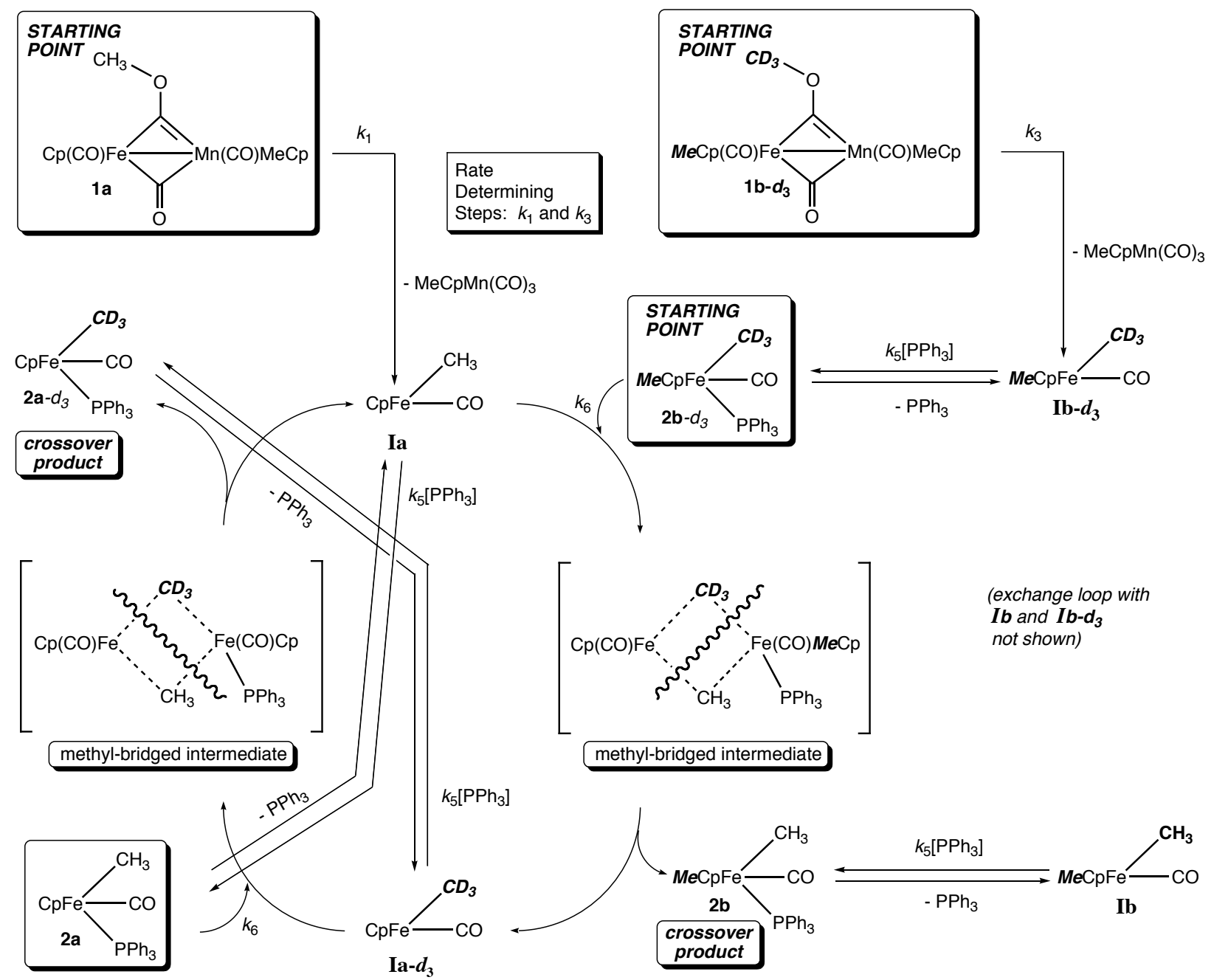

by $\mathbf{2 a}$ are unlikely and without precedent. The second problem with this mechanism is that $\mathbf{2 a}$ and $\mathbf{2 b}-d_{3}$ alone cannot be the starting points into the exchange cycle in the absence of carbynes - that is, entry into the catalytic cycle from $\mathbf{2 a}$ is required to be slow, because the products $\mathbf{2 a}$ and $\mathbf{2 b}-d_{3}$ do not exchange in the absence of 1a except after prolonged reaction. As described in the paper, this is not due to slow $\mathrm{PPh}_{3}$ dissociation.

Given the complexity of this system - up to seven organometallic species (including $\mathrm{MeCpMn}(\mathrm{CO})_{3}$ ) and four intermediates along with $\mathrm{PPh}_{3}-$ the system was quantitatively modeled using CRK2005. The reaction steps for Scheme S-3 are shown in Chart S-1. Results for this mechanism and data from runs 6, 9, and 10 involving the two carbynes and the two control crossover experiments run with different concentrations of product $\mathbf{2} \mathbf{b}-d_{3}$ are shown in Figure S1 , and rate constants are given in Table S-4; for convenience, rate constants for Scheme 6 are also included here. Graphs (a), (b), and (c) illustrate the best fits for the mechanism in Scheme S-3 to the carbyne crossover experiment (Figure S-1a, run 6), the control crossover experiment that starts with a $\sim 1: 1$ ratio of $\mathbf{1 a}$ and $\mathbf{2} \mathbf{b}-d_{3}$ (Figure $S-1 b$, run 9 ), and the control crossover experiment that starts with a 1:2.5 ratio of $\mathbf{1 a}$ and $\mathbf{2 b}-d_{3}$ (Figure $\mathrm{S}-1 \mathrm{c}$, run 10 ). As can be seen 
the fit is especially poor for $\mathbf{1 a}$ in run $10, \mathbf{2 a}$ in all three runs, $\mathbf{2} \mathbf{a}+\mathbf{2} \mathbf{a}-d_{3}$ in runs 6 and 10 , and for $\mathrm{MeCpMn}(\mathrm{CO})_{3}$ in runs 9 and 10. Some simplifications were used, namely that $k_{5}$ and $k_{6}$ were not allowed to differ for $\mathrm{CpFe}$ and $\mathrm{MeCpFe}$ species, and the rate of dissociation of $\mathrm{PPh}_{3}$ from the iron alkyls was set at $6 \square 10^{-5} \mathrm{~s}^{-1}$ as shown in eq 4, again for both $\mathrm{CpFe}$ and $\mathrm{MeCpFe}$ species. A better fit, particularly for runs 6 and 9, was obtained (graphs (d) - (f)) when each run was fit individually to the mechanism in Scheme S-3, but in this case, the best fit rate constants were different for each run! That is, as expected, one set of rate constants cannot be found to fit all three sets of initial conditions; surprisingly, even $k_{1}$ for each run is different, but as noted following eq 4, each of these values is still less than that of dissociative loss of $\mathrm{PPh}_{3}$ from $\mathbf{2 a}$. As can be seen, while the fit is much better for (d) - (f) in spite of the fact that different rate constants were permitted for each run, even so the fit is not good, particularly for $\mathbf{2} \mathbf{a}$ and $\mathbf{2 b}$ in runs 9 and 10. As expected from the discussion above of relative rates of trapping by phosphine compared to the iron alkyls, the values of $k_{5} / k_{6}$ must be different in each run in order to even allow the imperfect fits shown. That is, at the high concentration of $\mathbf{2} \mathbf{b}-d_{3}, k_{5}$ must be relatively high in order for comparable amounts of $\mathbf{2} \mathbf{a}$ and $\mathbf{2} \mathbf{b}$ to form, giving rapid trapping of $\mathrm{CpFe}(\mathrm{CO}) \mathrm{Me}$ by $\mathrm{PPh}_{3}$ in order to prevent near-exclusive formation of $\mathbf{2} \mathbf{b}$ at the expense of $\mathbf{2 a}$ by methyl exchange in the $k_{6}$ step, and so $k_{5} / k_{6}=1.4 \pm 0.2$. In the carbyne crossover, on the other hand, a high value of $k_{5} / k_{6}$ would eliminate any exchange and so very little $\mathbf{2 b}$ would form; in order to fit this run, then, a value of $k_{5} / k_{6}$ roughly $100 \square$ smaller was found, $k_{5} / k_{6}=0.013 \pm 0.008$. Hence, while the system is complex, there are no counter-intuitive surprises buried in the kinetic equations. The conflicting requirements of product formation $\left(k_{5}\right)$ and equilibration $\left(k_{6}\right)$ require that a common intermediate cannot lead to both pathways, and quantitatively, the simple mechanism in Scheme S-3 and Chart S-1 is wrong.

\section{References}

(1) Kazlauskas, R. J.; Wrighton, M. S. Organometallics 1982, 1, 602-611.

(2) McFarlane, K. L.; Ford, P. C. Organometallics 1998, 17, 1166-1168.

\section{Chart S-1. Reaction Steps for Scheme S-3}

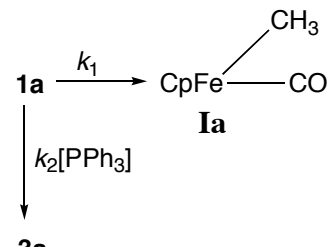

$3 a$

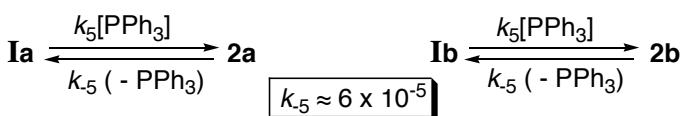

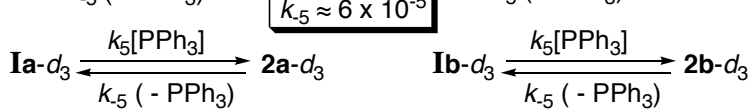

$\mathbf{I a}+\mathbf{2} \mathbf{a}-d_{3} \underset{k_{6}}{\stackrel{k_{6}}{\rightleftarrows}} \mathbf{I a}-d_{3}+\mathbf{2} \mathbf{a} \quad \mathbf{I b}+\mathbf{2} \mathbf{a}-d_{3} \underset{k_{6}}{\stackrel{k_{6}}{\rightleftarrows}} \mathbf{I b}-d_{3}+\mathbf{2} \mathbf{a}$

$\mathbf{I a}+\mathbf{2} \mathbf{b}-d_{3} \underset{k_{6}}{\stackrel{k_{6}}{\rightleftarrows}} \mathbf{I a}-d_{3}+\mathbf{2} \mathbf{b}$

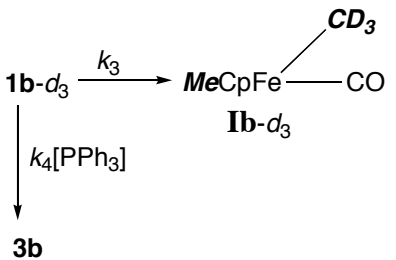

$\mathbf{I b}+\mathbf{2} \mathbf{b}-d_{3} \underset{k_{6}}{\stackrel{k_{6}}{\rightleftarrows}} \mathbf{I b}-d_{3}+\mathbf{2} \mathbf{b}$ 
(a) Carbyne Crossover (Scheme S-3, run 6)

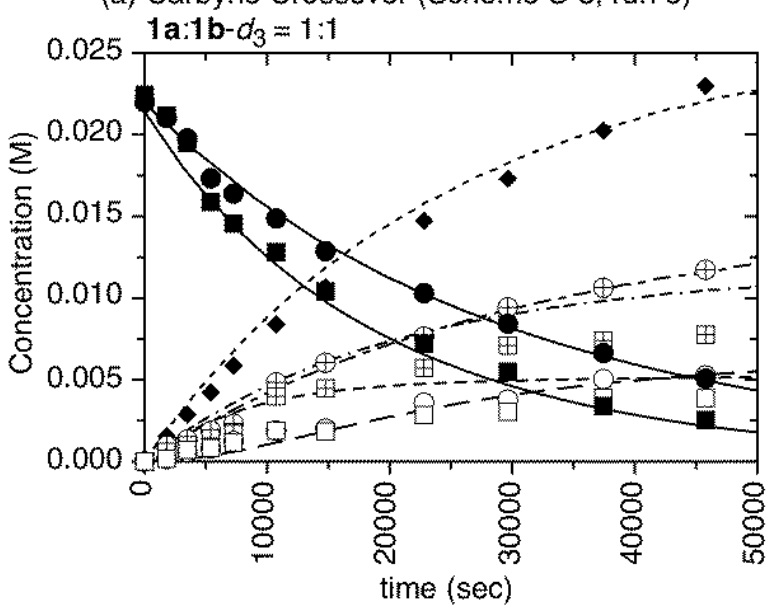

(b) Control Crossover (Scheme S-3, run 9)

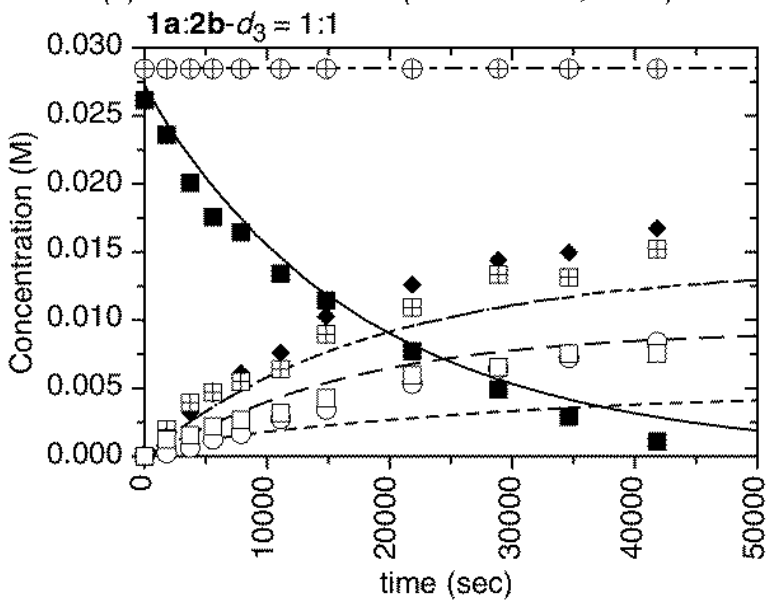

(c) Control Crossover (Scheme S-3, run 10)

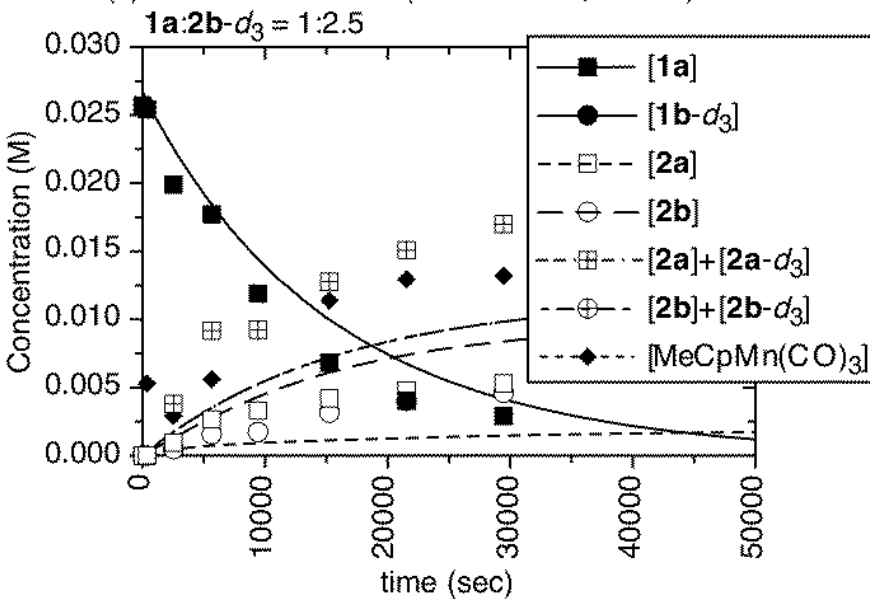

(d) Carbyne Crossover (Scheme S-3, run 6 alone)

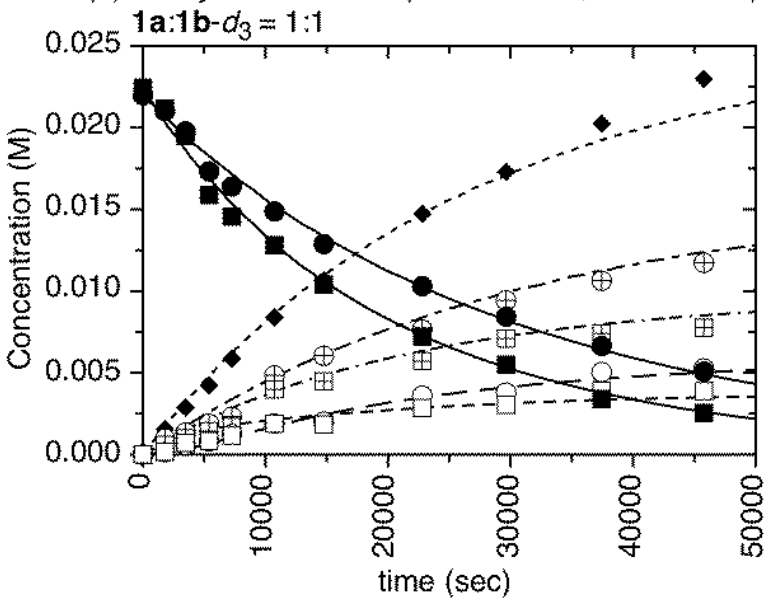

(e) Control Crossover (Scheme S-3, run 9 alone)

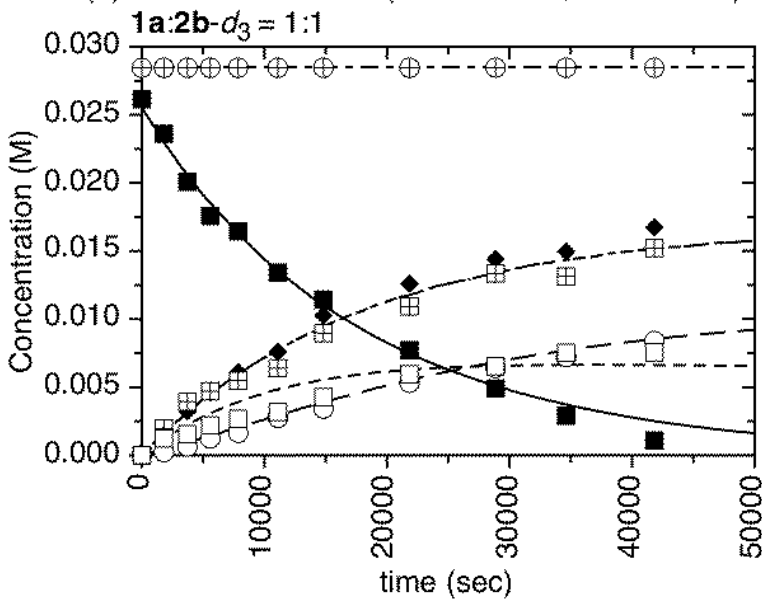

(f) Control Crossover (Scheme S-3, run 10 alone)

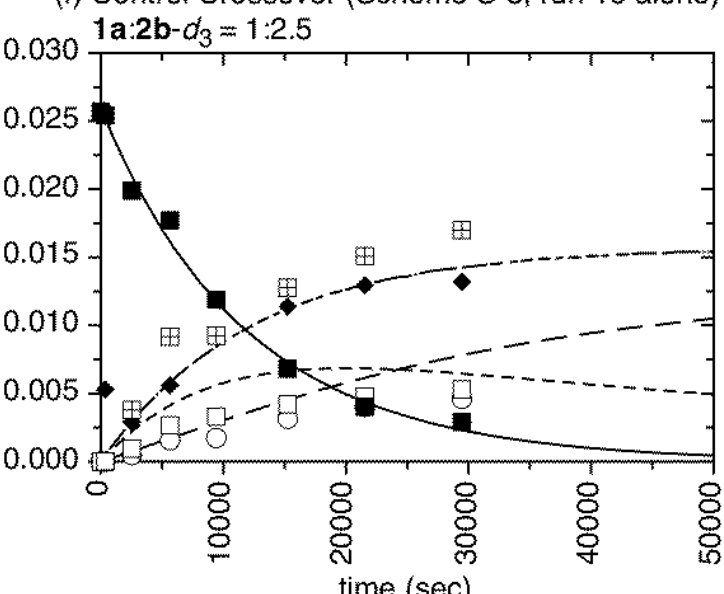

Figure S-1. Best fit of Scheme S-3 mechanism, using the equations from Chart S-1, to observed concentration data for Runs 6,9 , and 10 , for (a) - (c) at $65^{\circ} \mathrm{C}$. For (d) - (f), rate constants were allowed to vary to give the best fit to each run alone. Values for the sets of rate constants used are given in Table S-4. The calculated lines for [2a] $+\left[\mathbf{2 a}-d_{3}\right]$ and $\mathrm{MeCpMn}(\mathrm{CO})_{3}$ are coincident for runs 9 and 10 , and the line for $[\mathbf{2 b}]+\left[\mathbf{2} \mathbf{b}-d_{3}\right]$ at $0.063 \mathrm{M}$ is not shown in run 10 ; it is an exact fit just as seen for the $0.028 \mathrm{M}$ line for $[\mathbf{2 b}]+\left[\mathbf{2 b}-d_{3}\right]$ in run 9 . 
Table S-4. Rate constants at $65^{\circ} \mathrm{C}$ for mechanisms in Charts S-1 and Chart 1.

\begin{tabular}{|c|c|c|c|c|c|}
\hline & \multicolumn{4}{|c|}{ Rate Constants for Mechanism in Scheme S-3 } & Scheme 6 \\
\hline Rate constant & Runs $6,9,10$ & Run 6 alone & Run 9 alone & Run 10 alone & Runs 6,9,10 \\
\hline$k_{1}\left(\mathrm{~s}^{-1}\right)^{a}$ & $2.79 \pm 0.12$ & $2.10 \pm 0.04$ & $3.69 \pm 0.05$ & $5.01 \pm 0.17$ & $4.66 \pm 0.12$ \\
\hline$k_{2}\left(\mathrm{M}^{-1} \mathrm{~s}^{-1}\right)^{a}$ & $24.0 \pm 2.1$ & $28.4 \pm 0.9$ & $17.0 \pm 0.7$ & $22.0 \pm 1.8$ & $22.5 \pm 1.1$ \\
\hline$k_{3}\left(\mathrm{~s}^{-1}\right)^{a}$ & $2.25 \pm 0.13$ & $2.39 \pm 0.04$ & - & - & $5.55 \pm 0.17$ \\
\hline$k_{4}\left(\mathrm{M}^{-1} \mathrm{~s}^{-1}\right)^{a}$ & $10.9 \pm 2.2$ & $9.44 \pm 0.64$ & - & - & $8.5 \pm 1.1$ \\
\hline$k_{5} / k_{6}$ & $0.17 \pm 0.11$ & $0.013 \pm 0.008$ & $0.70 \pm 0.04$ & $1.38 \pm 0.16$ & $6.2 \square 10^{-10 b}$ \\
\hline$k_{7} / k_{6}$ & & & & & $1.21 \pm 0.04$ \\
\hline$f_{8}$ & & & & & $0.65 \pm 0.03$ \\
\hline$\square_{\square}^{2 c}$ & 3.12 & 0.72 & 0.46 & 1.01 & 0.952 \\
\hline$\%$ error $^{c}$ & 16.7 & 7.26 & 5.68 & 8.53 & 9.17 \\
\hline data points & 191 & 77 & 66 & 48 & 191 \\
\hline
\end{tabular}

${ }^{a}$ For $k_{1}-k_{4}, \square 10^{5} .{ }^{b}$ Range for $k_{5} / k_{6}=2 \square 10^{-12}$ to $2 \square 10^{-7}$. ${ }^{c}$ See Experimental Section for an explanation of the deviations, $\square_{\square}^{2}$, and the $\%$ error. 
Chart S-2. Differential Equations for Scheme S-3.

$d[\mathbf{1 a}] / d t=-\left(k_{1}+k_{2}\left[\mathrm{PPh}_{3}\right]\right)[\mathbf{1} \mathbf{a}]$

$d\left[\mathbf{1 b}-d_{3}\right] / d t=-\left(k_{3}+k_{4}\left[\mathrm{PPh}_{3}\right]\right)\left[\mathbf{1 b}-d_{3}\right]$

$d[\mathbf{2 a}] / d t=k_{5}[\mathbf{I} \mathbf{a}]\left[\mathrm{PPh}_{3}\right]-k_{-5}[\mathbf{2} \mathbf{a}]+k_{6}\left[\mathbf{2} \mathbf{a}-d_{3}\right]([\mathbf{I a}]+[\mathbf{I} \mathbf{b}])-k_{6}[\mathbf{2} \mathbf{a}]\left(\left[\mathbf{I} \mathbf{a}-d_{3}\right]+\left[\mathbf{I b}-d_{3}\right]\right)$

$d[\mathbf{2} \mathbf{b}] / d t=k_{5}[\mathbf{I b}]\left[\mathrm{PPh}_{3}\right]-k_{-5}[\mathbf{2} \mathbf{b}]+k_{6}\left[\mathbf{2} \mathbf{b}-d_{3}\right]([\mathbf{I a}]+[\mathbf{I b}])-k_{6}[\mathbf{2} \mathbf{b}]\left(\left[\mathbf{I a}-d_{3}\right]+\left[\mathbf{I} \mathbf{b}-d_{3}\right]\right)$

$d\left[\mathbf{2} \mathbf{a}-d_{3}\right] / d t=k_{5}\left[\mathbf{I a}-d_{3}\right]\left[\mathrm{PPh}_{3}\right]-k_{-5}\left[\mathbf{2} \mathbf{a}-d_{3}\right]+k_{6}[\mathbf{2} \mathbf{a}]\left(\left[\mathbf{I a}-d_{3}\right]+\left[\mathbf{I} \mathbf{b}-d_{3}\right]\right)-k_{6}\left[\mathbf{2} \mathbf{a}-d_{3}\right]([\mathbf{I a}]+[\mathbf{I b}])$

$d\left[\mathbf{2} \mathbf{b}-d_{3}\right] / d t=k_{5}\left[\mathbf{I b}-d_{3}\right]\left[\mathrm{PPh}_{3}\right]-k_{-5}\left[\mathbf{2} \mathbf{b}-d_{3}\right]+k_{6}[\mathbf{2 b}]\left(\left[\mathbf{I} \mathbf{a}-d_{3}\right]+\left[\mathbf{I} \mathbf{b}-d_{3}\right]\right)-k_{6}\left[\mathbf{2} \mathbf{b}-d_{3}\right]([\mathbf{I a}]+[\mathbf{I} \mathbf{b}])$

$d\left[\mathrm{MeCpMn}(\mathrm{CO})_{3}\right] / d t=k_{1}[\mathbf{1} \mathbf{a}]+k_{3}\left[\mathbf{1 b}-d_{3}\right]$

$d\left[\mathrm{PPh}_{3}\right] / d t=k_{-5}\left([\mathbf{2} \mathbf{a}]+[\mathbf{2} \mathbf{b}]+\left[\mathbf{2} \mathbf{a}-d_{3}\right]+\left[\mathbf{2} \mathbf{b}-d_{3}\right]\right)-\left[\mathrm{PPh}_{3}\right]\left\{k_{2}[\mathbf{1} \mathbf{a}]+k_{4}\left[\mathbf{1} \mathbf{b}-d_{3}\right]+k_{5}\left([\mathbf{I a}]+[\mathbf{I b}]+\left[\mathbf{I a}-d_{3}\right]+\left[\mathbf{I b}-d_{3}\right]\right)\right\}$

$d[\mathbf{I a}] / d t=k_{1}[\mathbf{1} \mathbf{a}]+k_{-5}[\mathbf{2} \mathbf{a}]+k_{6}\left[\mathbf{I a}-d_{3}\right]([\mathbf{2} \mathbf{a}]+[\mathbf{2} \mathbf{b}])-k_{6}[\mathbf{I a}]\left(\left[\mathbf{2} \mathbf{a}-d_{3}\right]+\left[\mathbf{2} \mathbf{b}-d_{3}\right]\right)-k_{5}[\mathbf{I a}]\left[\mathrm{PPh}_{3}\right]$

$d[\mathbf{I b}] / d t=k_{-5}[\mathbf{2} \mathbf{b}]+k_{6}\left[\mathbf{I b}-d_{3}\right]([\mathbf{2} \mathbf{a}]+[\mathbf{2} \mathbf{b}])-k_{6}[\mathbf{I b}]\left(\left[\mathbf{2} \mathbf{a}-d_{3}\right]+\left[\mathbf{2} \mathbf{b}-d_{3}\right]\right)-k_{5}[\mathbf{I} \mathbf{b}]\left[\mathrm{PPh}_{3}\right]$

$d\left[\mathbf{I a}-d_{3}\right] / d t=k_{-5}\left[\mathbf{2} \mathbf{a}-d_{3}\right]+k_{6}[\mathbf{I a}]\left(\left[\mathbf{2} \mathbf{a}-d_{3}\right]+\left[\mathbf{2} \mathbf{b}-d_{3}\right]\right)-k_{6}\left[\mathbf{I a}-d_{3}\right]([\mathbf{2} \mathbf{a}]+[\mathbf{2} \mathbf{b}])-k_{5}\left[\mathbf{I a}-d_{3}\right]\left[\mathrm{PPh}_{3}\right]$

$d\left[\mathbf{I b}-d_{3}\right] / d t=k_{3}\left[\mathbf{1 b}-d_{3}\right]+k_{-5}\left[\mathbf{2} \mathbf{b}-d_{3}\right]+k_{6}[\mathbf{I b}]\left(\left[\mathbf{2} \mathbf{a}-d_{3}\right]+\left[\mathbf{2} \mathbf{b}-d_{3}\right]\right)-k_{6}\left[\mathbf{I b}-d_{3}\right]([\mathbf{2 a}]+[\mathbf{2} \mathbf{b}])-k_{5}\left[\mathbf{I b}-d_{3}\right]\left[\mathrm{PPh}_{3}\right]$

$k_{-5} \approx 6 \square 10^{-5}$

\section{Chart S-3. Differential Equations for Scheme 6.}

$d[\mathbf{1 a}] / d t=-\left(k_{1}+k_{2}\left[\mathrm{PPh}_{3}\right]\right)[\mathbf{1 a}]+k_{7}\left[\mathrm{MeCpMn}(\mathrm{CO})_{3}\right]\left[\mathbf{I}_{1}\right]$

$d\left[\mathbf{1 b}-\mathrm{d}_{3}\right] / d t=-\left(k_{3}+k_{4}\left[\mathrm{PPh}_{3}\right]\right)\left[\mathbf{1 b}-\mathrm{d}_{3}\right]+k_{7}\left[\operatorname{MeCpMn}(\mathrm{CO})_{3}\right]\left[\mathbf{I}_{2}\right]$

$d[\mathbf{2} \mathbf{a}] / d t=k_{5}\left[\mathbf{I}_{1}\right]\left[\mathrm{PPh}_{3}\right]+k_{6}\left[\mathbf{I}_{1}\right]\left\{[\mathbf{2} \mathbf{a}]+[\mathbf{2} \mathbf{b}]+\left[\mathbf{2} \mathbf{a}-\mathrm{d}_{3}\right]+\left(1-f_{8}\right)\left[\mathbf{2} \mathbf{b}-\mathrm{d}_{3}\right]\right\}-k_{6} f_{8}\left[\mathbf{I}_{2}\right][\mathbf{2} \mathbf{a}]$

$d[\mathbf{2} \mathbf{b}] / d t=k_{6} f_{8}\left[\mathbf{I}_{1}\right]\left[\mathbf{2} \mathbf{b}-\mathrm{d}_{3}\right]+k_{6} f_{8}\left[\mathbf{I}_{2}\right][\mathbf{2} \mathbf{a}]$

$d\left[\mathbf{2} \mathbf{a}-\mathrm{d}_{3}\right] / d t=k_{6} f_{8}\left[\mathbf{I}_{1}\right]\left[\mathbf{2} \mathbf{b}-\mathrm{d}_{3}\right]+k_{6} f_{8}\left[\mathbf{I}_{2}\right][\mathbf{2} \mathbf{a}]$

$d\left[\mathbf{2} \mathbf{b}-\mathrm{d}_{3}\right] / d t=k_{5}\left[\mathbf{I}_{2}\right]\left[\mathrm{PPh}_{3}\right]-k_{6} f_{8}\left[\mathbf{I}_{1}\right]\left[\mathbf{2} \mathbf{b}-\mathrm{d}_{3}\right]+k_{6}\left[\mathbf{I}_{2}\right]\left\{\left(1-f_{8}\right)[\mathbf{2} \mathbf{a}]+[\mathbf{2} \mathbf{b}]+\left[\mathbf{2} \mathbf{a}-\mathrm{d}_{3}\right]+\left[2 \mathbf{b}-\mathrm{d}_{3}\right]\right\}$

$d\left[\mathrm{MeCpMn}(\mathrm{CO})_{3}\right] / d t=k_{1}[\mathbf{1 a}]+k_{3}\left[\mathbf{1} \mathbf{b}-\mathrm{d}_{3}\right]-k_{7}\left[\operatorname{MeCpMn}(\mathrm{CO})_{3}\right]\left(\left[\mathbf{I}_{1}\right]+\left[\mathbf{I}_{2}\right]\right)$

$d\left[\mathrm{PPh}_{3}\right] / d t=-\left[\mathrm{PPh}_{3}\right]\left\{k_{2}[\mathbf{1 a}]+k_{4}\left[\mathbf{1} \mathbf{b}-\mathrm{d}_{3}\right]+k_{5}\left(\left[\mathbf{I}_{1}\right]+\left[\mathbf{I}_{2}\right]\right)+k_{6}\left(\left[\mathbf{I}_{1}\right]+\left[\mathbf{I}_{2}\right]\right)\left([\mathbf{2} \mathbf{a}]+[\mathbf{2} \mathbf{b}]+\left[\mathbf{2} \mathbf{a}-\mathrm{d}_{3}\right]+\left[\mathbf{2} \mathbf{b}-\mathrm{d}_{3}\right]\right)\right\}$

$d\left[\mathbf{I}_{1}\right] / d t=k_{1}[\mathbf{1} \mathbf{a}]-\left[\mathbf{I}_{1}\right]\left\{k_{7}\left[\operatorname{MeCpMn}(\mathrm{CO})_{3}\right]+k_{5}\left[\mathrm{PPh}_{3}\right]+k_{6}\left([\mathbf{2} \mathbf{a}]+[\mathbf{2} \mathbf{b}]+\left[\mathbf{2} \mathbf{a}-\mathrm{d}_{3}\right]+\left[\mathbf{2} \mathbf{b}-\mathrm{d}_{3}\right]\right)\right\}$

$d\left[\mathbf{I}_{2}\right] / d t=k_{3}\left[\mathbf{1} \mathbf{b}-\mathrm{d}_{3}\right]-\left[\mathbf{I}_{2}\right]\left\{k_{7}\left[\operatorname{MeCpMn}(\mathrm{CO})_{3}\right]+k_{5}\left[\mathrm{PPh}_{3}\right]+k_{6}\left([\mathbf{2} \mathbf{a}]+[\mathbf{2} \mathbf{b}]+\left[\mathbf{2} \mathbf{a}-\mathrm{d}_{3}\right]+\left[\mathbf{2} \mathbf{b}-\mathrm{d}_{3}\right]\right)\right\}$ 


\section{Fortran program \\ CRK2005 (with subroutine for Scheme 6)}

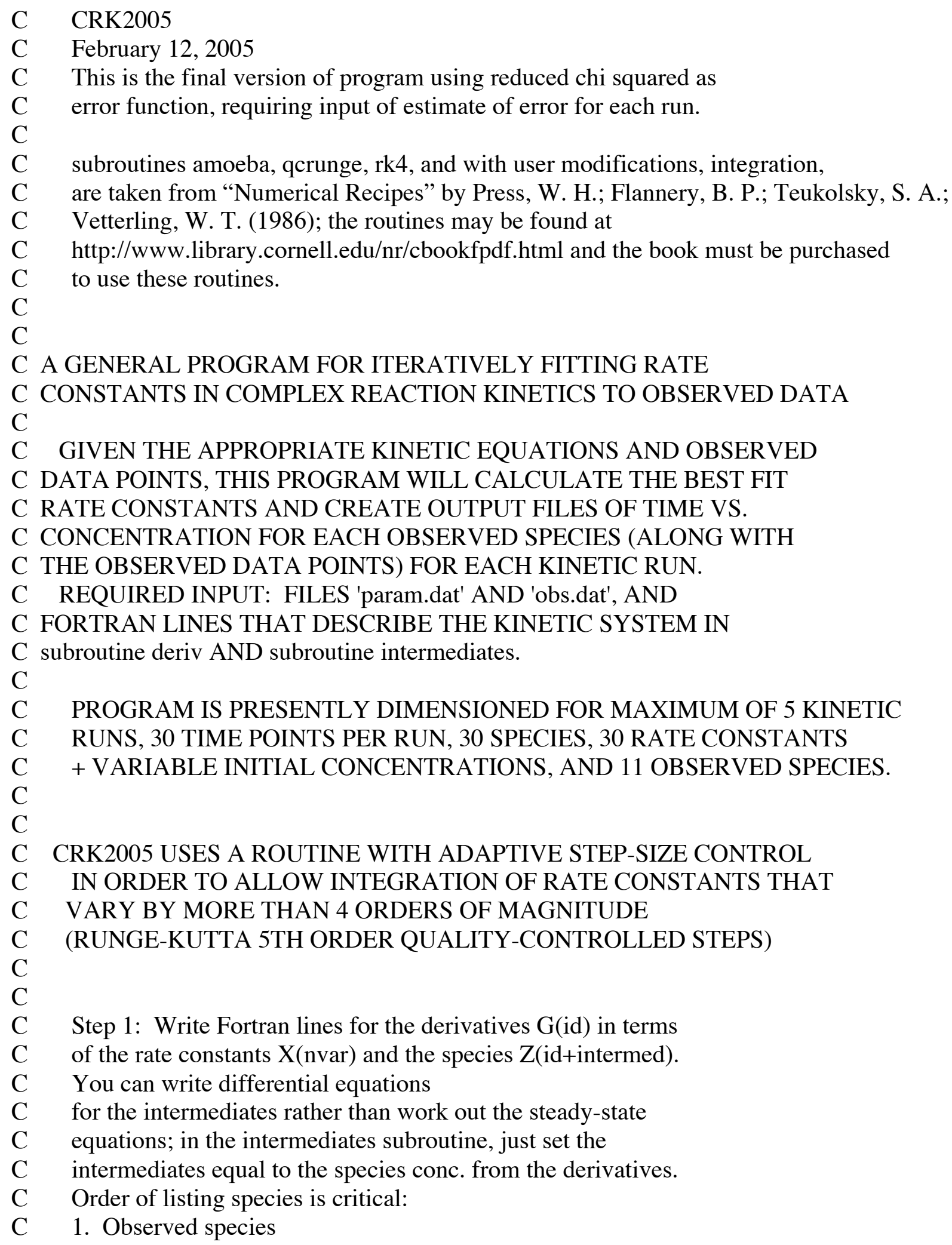


C 3. Intermediates (that will be set to approx 0 concentration).

C A suggestion: rather than use pseudo-first order concentrations

$\mathrm{C}$ (of PPh3, for instance), write derivative for this and allow

$\mathrm{C}$ it to decline during the reaction.

C Step 2: compile according to your system. This version

$\mathrm{C}$ has been migrated to a UNIX machine, which cannot

C overwrite files, and so creates a new output file, ratesfinal.dat.

$\mathrm{C}$ Rate equations are added at the end of the fortran code in

C two subroutines and compiled in FORTRAN 77

$\mathrm{C}$ to give a.out command in UNIX.

implicit real*8(a-h,o-z $)$

dimension $\mathrm{x}(30), \mathrm{z}(30), \mathrm{dxtmp}(30), \mathrm{p}(31,30), \mathrm{y}(31)$

common/a/dx(30),calc(30,30),biconc(2,5),ja,jb,simulation

common/b/cobs(12,5,30),sigma(5),tf(5),ztzero(30,5),np(5)

common/c/hstore,pc,pcintermed,eps,hmin,hmax,errmax,ipoints

common/d/nvar,nvarinit,id,iobs,intermed

common/e/tt(1001),zz(30,1001), mapz(60)

open (unit=1, name='param.dat',type $=$ 'old')

C SET OPTIONS: rates $=1$ MEANS rates

C ARE READ IN FROM rates.dat FILE.

C IF simulation $=1$, THEN INITIAL CONCENTRATIONS ARE ALSO

C READ IN FROM rates.dat FILE IF rates $=1$.

C However, if you don't want a rate to be varied, set the

C step size to 0 in the param.dat file.

$\mathrm{C}$ simulation $=1$ MEANS NO ITERATIONS ARE DONE.

C output $=1$ MEANS PRINT OUTPUT DATA FOR ALL SPECIES.

C erroranalysis $=1$ means carry out error analysis

$\operatorname{read}(1, *)$ rates, simulation, output,erroranalysis

C id IS \#derivATIVES, iobs \#OBSERVED SPECIES, intermed \#

C OF STEADY STATE INTERMEDIATES,

$\mathrm{C}$ pcintermed IS \% OF MAX CONC OF ANY OBSERVED SPECIES THAT

$\mathrm{C}$ IS ALLOWED FOR HIGHEST CONC OF A "STEADY-STATE" INTERMEDIATE,

C nvar \#RATE CONSTANTS,

C nvarinit \# OF STARTING MATERIALS per run WHOSE CONCNTRATIONS ARE

C ALLOWED TO VARY, jb \# OF KINETIC RUNS, ibi \# OF PSEUDO-

C FIRST ORDER BIMOLECULAR COMPONENTS, hstore ESTIMATED \# OF CALC

C PTS PER LINE, eps (EPSILON) IS ACCURACY TOLERANCE REQUIRED OF

C INTEGRATION, pc PERCENT TOLERANCE IN CHANGE IN ERROR FUNCTION

C BELOW WHICH ITERATION STOPS, ipoints \#OUTPUT POINTS TO PLOT,

$\mathrm{C}$ isets \#OF TIMES ITERATION RESTARTS - ALL IN FIRST LINE OF

C param.dat FILE

C GOOD VALUES ARE hstore $=1000$, eps $=0.01, \mathrm{pc}=0.01$, ipoints $=50$,

$\mathrm{C}$ isets=3; PRESUMABLY pcintermed WILL BE WELL BELOW 1 BUT IF

C VERY LARGE DIFFERENCES IN RATE CONSTANTS (I.E. 1E+8) ARE 
C NECESSARY, COMPUTATIONS WILL BE FASTER IF pcintermed $=1$.

read $(1, *)$ id,iobs,intermed,pcintermed,nvar,nvarinit,jb,ibi,

1 hstore,eps,pc,ipoints,isets

C ENTER \# OF POINTS PER RUN, FINAL TIME POINT FOR INTEGRATION

C FOR EACH RUN ON ONE LINE,

C and sigma for each run - absolute error in concentration, per data point. $\operatorname{read}(1, *)(n p(i), t f(i), \operatorname{sigma}(i), i=1, j b)$

C ENTER EACH RATE CONSTANT AND ITS STEP SIZE ON ONE LINE $\operatorname{read}\left(1,{ }^{*}\right)(x(\mathrm{i}), \mathrm{dx}(\mathrm{i}), \mathrm{i}=1, \mathrm{nvar})$

C INPUT RUN \#, SPECIES \# (I.E. SAME AS Z(\#) OR G(\#) IN

C deriv SUBROUTINE), STEP SIZE - NOTE!!! - STEP SIZE

C MUST BE SET TO THE MAXIMUM ACCEPTABLE DEVIATION FROM

C INPUT CONCENTRATION

do $112 \mathrm{i}=1$,nvarinit*jb

$112 \operatorname{read}(1, *) \operatorname{mapz}(2 * \mathrm{i}-1), \operatorname{mapz}(2 * \mathrm{i}), \mathrm{dx}($ nvar+i)

close(unit=1)

C CUT STEP SIZE BY 4 SO THAT SIMPLEX DOES NOT IMMEDIATELY

C NEED TO CHANGE THIS STEP.

do $111 \mathrm{i}=1$,nvarinit* jb

$111 \mathrm{dx}($ nvar+i $)=\mathrm{dx}($ nvar+i $) / 4$

open (unit=2,name='obs.dat',type='old')

do $1 \mathrm{ja}=1, \mathrm{jb}$

C FIRST LINE OF obs.dat FILE MUST CONTAIN ALL INITIAL

C CONCENTRATIONS (INCLUDING INTERMEDIATES)

do $2 \mathrm{k}=1, \mathrm{np}(\mathrm{ja})$

if(k.ne.1)goto 3

C ALL RUNS ARE ASSUMED TO START AT T $=0$

$\operatorname{read}\left(2,{ }^{*}\right) \operatorname{cobs}(1, \mathrm{ja}, 1),(\mathrm{ztzero}(\mathrm{i}, \mathrm{ja}), \mathrm{i}=1, \mathrm{id})$

do $4 \mathrm{i}=1$,iobs

$4 \operatorname{cobs}(\mathrm{i}+1, \mathrm{ja}, 1)=$ ztzero $(\mathrm{i}, \mathrm{ja})$

goto 2

$3 \operatorname{read}\left(2,{ }^{*}\right)(\operatorname{cobs}(\mathrm{i}, \mathrm{ja}, \mathrm{k}), \mathrm{i}=1, \mathrm{iobs}+1)$

2 continue

do $5 \mathrm{i}=1$,ibi

$5 \operatorname{read}(2, *)$ biconc(i,ja)

1 continue

close(unit=2)

if(rates.eq.1) then

open( unit $=3$,name $=$ 'rates.dat',type $=$ 'old')

$\operatorname{read}(3, *)(x(i), i=1$, nvar $)$

C set step sizes equal to input rates, because these may be

C be very different from those in param.dat UNLESS step size

$\mathrm{C}$ is zero in the param.dat file, in which case it will be

C left at zero and the rate will not be varied.

do $751 \mathrm{i}=1$,nvar

if(dx(i).eq.0) goto 751 


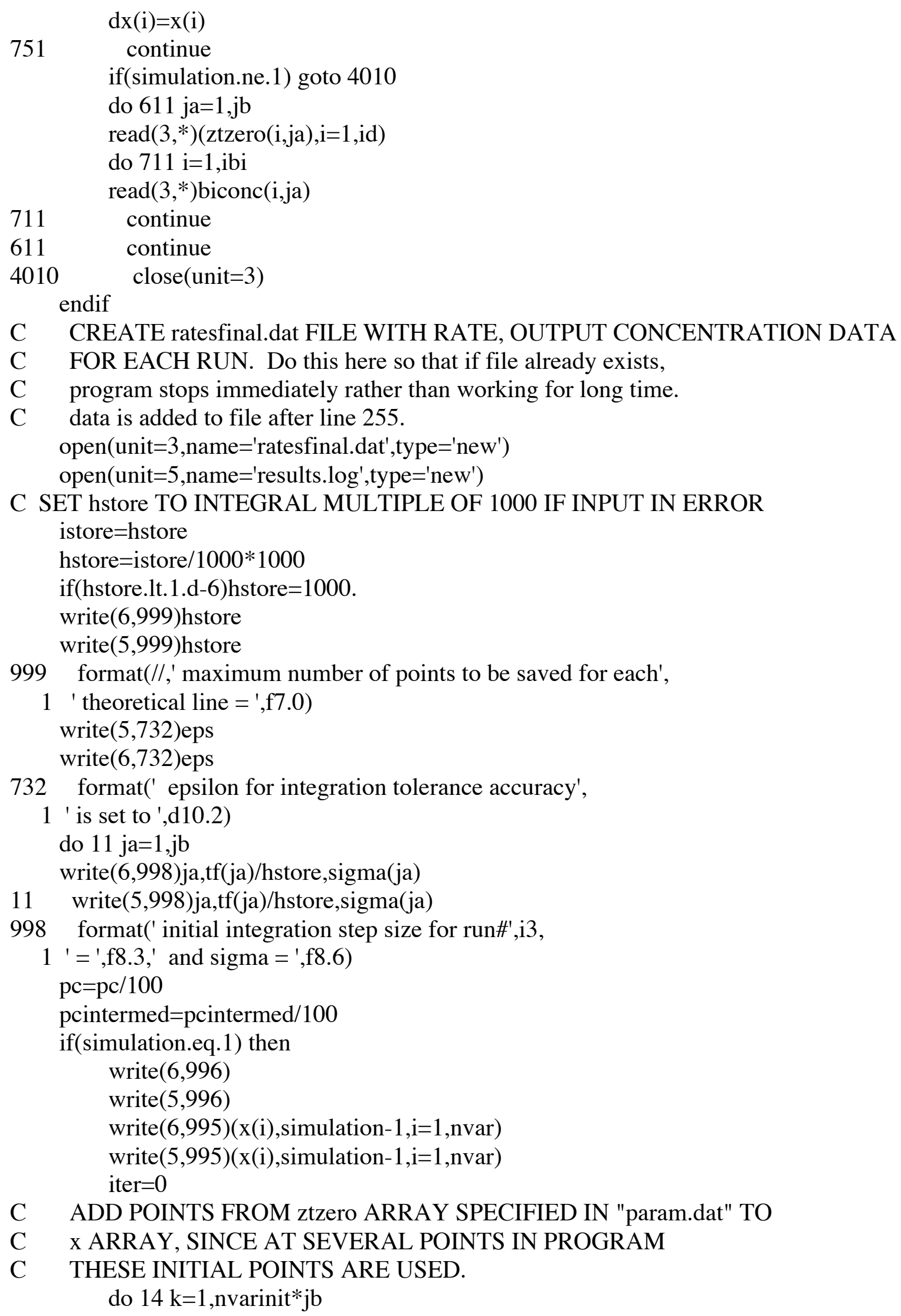

C SET hstore TO INTEGRAL MULTIPLE OF 1000 IF INPUT IN ERROR istore $=$ hstore 
$14 \quad \mathrm{x}(\mathrm{nvar}+\mathrm{k})=\mathrm{ztzero}(\operatorname{mapz}(2 * \mathrm{k}), \operatorname{mapz}(2 * \mathrm{k}-1))$

errorfinal=error $(\mathrm{x})$

endif

goto 575

isets $1=0$

100 isets $1=$ isets $1+1$

write $(6,997)$ isets 1 ,isets

write $(5,997)$ isets 1 , isets

997 format(//,' iteration set ',i3,' of ',i3)

if(isets1.eq.1)go to 12

C AFTER FIRST ITERATION SET, PROGRAM SETS 1) STEP SIZES FOR

C CALC RATE CONSTANTS (CUTTING BY 2 EACH TIME) AND 2) \% CHANGE

C IN ERROR FUNCTION FOR ITERATION TERMINATION (CUTTING BY

C 2 EACH TIME)

do $13 \mathrm{i}=1$,nvar

$13 \mathrm{dx}(\mathrm{i})=\mathrm{dx}(\mathrm{i}) / 2$.

$\mathrm{pc}=\mathrm{pc} / 2$.

12 write $(6,996)$

write $(5,996)$

996 format(/,' input rates step size')

write $(6,995)(x(i), d x(i), i=1, n v a r)$

write $(5,995)(x(i), d x(i), i=1, n v a r)$

995 format(1h,d12.5,3x,d12.5)

C ADD POINTS FROM ztzero ARRAY SPECIFIED IN "param.dat" TO

C $x$ ARRAY, ALLOWING THESE POINTS TO BE VARIED IN

C MINIMIZATION ROUTINE amoeba.

$\mathrm{C}$ IF THIS IS THE SECOND SET OF ITERATIONS, INITIAL POINTS IN $\mathrm{x}$

C ARE RESET TO THEIR INITIAL VALUES FROM ztzero.

do $414 \mathrm{k}=1$,nvarinit*jb

$414 \quad \mathrm{x}(\mathrm{nvar}+\mathrm{k})=\mathrm{ztzero}(\operatorname{mapz}(2 * \mathrm{k}), \operatorname{mapz}(2 * \mathrm{k}-1))$

do $15 \mathrm{k}=1$,nvarinit*jb

write $(6,994) \operatorname{mapz}(2 * \mathrm{k}), \operatorname{mapz}(2 * \mathrm{k}-1), \mathrm{x}(\mathrm{nvar}+\mathrm{k}), 4 * \mathrm{dx}(\mathrm{nvar}+\mathrm{k})$

15 write $(5,994) \operatorname{mapz}(2 * \mathrm{k}), \operatorname{mapz}(2 * \mathrm{k}-1), \mathrm{x}(\mathrm{nvar}+\mathrm{k}), 4 * \mathrm{dx}(\mathrm{nvar}+\mathrm{k})$

994 format(' initial conc. for species \#',i2,' in run \#',i2,

1 '= ',f10.7,' max. dev. = ',f10.7)

C INITIALIZE SIMPLEX VERTICES USING INPUT RATE CONSTANTS, OR

C RE-INITIALIZE USING MINIMIZED SET OF RATE CONSTANTS, AND

$\mathrm{C}$ USE INITIAL STEP SIZES AND INITIAL CONCENTRATIONS.

do $21 \mathrm{j}=1, n v a r+n v a r i n i t * j b+1$

do $22 \mathrm{i}=1$,nvar+nvarinit*jb

$22 \mathrm{p}(\mathrm{j}, \mathrm{i})=\mathrm{x}(\mathrm{i})$

21 continue

do $23 \mathrm{i}=1$,nvar+nvarinit*jb

$23 \mathrm{p}(\mathrm{i}+1, \mathrm{i})=\mathrm{p}(\mathrm{i}+1, \mathrm{i})+\mathrm{dx}(\mathrm{i})$

do $24 \mathrm{j}=1$,nvar+nvarinit $* \mathrm{jb}+1$

do $25 \mathrm{i}=1$,nvar+nvarinit $* \mathrm{jb}$ 
$25 \quad \mathrm{x}(\mathrm{i})=\mathrm{p}(\mathrm{j}, \mathrm{i})$

$y(j)=\operatorname{error}(x)$

if(j.eq.1) then

write $(6,498) \mathrm{y}(1)$

write $(5,498) y(1)$

498 format(' error for current rate constants =',f15.7)

write $(6,722)$ hmin,hmax

write $(5,722)$ hmin,hmax

722 format(' minimum and maximum step sizes used were ',

$1 \mathrm{~d} 8.2$,' and ',f8.2,' seconds')

endif

24 continue

$\mathrm{mp}=$ nvar+nvarinit $* \mathrm{jb}+1$

nps $=$ nvar+nvarinit $*$ jb

ndim $=$ nvar+nvarinit $* j b$

ftol $=\mathrm{pc}$

iter $=0$

call amoeba(p,y,mp,nps,ndim,ftol,error,iter)

do $32 \mathrm{i}=1$,nvar+nvarinit* $\mathrm{jb}$

$32 \quad \mathrm{x}(\mathrm{i})=\mathrm{p}(1, \mathrm{i})$

if(isets1.lt.isets)go to 100

C JIGGLE RC'S, SINCE SIMPLEX SOMETIMES FAILS TO FIND BEST errorfinal=error $(\mathrm{x})$

630 do $631 \mathrm{i}=1$,nvar

if(dx(i).eq.0) goto 631

$\mathrm{xtmp}=\mathrm{x}(\mathrm{i})$

$\mathrm{x}(\mathrm{i})=\mathrm{xtmp} * 1.005$

errnew $=$ error $(\mathrm{x})$

if(errnew.lt.errorfinal) then

errorfinal=errnew

write $(5,9612) \mathrm{i}, \mathrm{x}(\mathrm{i})$,errorfinal

write $(6,9612) \mathrm{i}, \mathrm{x}(\mathrm{i})$,errorfinal

goto 630

endif

$x(i)=x \operatorname{tmp} * 0.995$

errnew=error $(\mathrm{x})$

if(errnew.lt.errorfinal) then

errorfinal=errnew

write $(5,9612) \mathrm{i}, \mathrm{x}(\mathrm{i})$,errorfinal

write $(6,9612) \mathrm{i}, \mathrm{x}(\mathrm{i})$, ,errorfinal

goto 630

endif

$x(i)=x \operatorname{tmp}$

631 continue

9612 format('Simplex did not find the best rc for rate \#',i3,

1 ' better value is ',d15.8,' and new error is ',f14.8) 
write $(6,980)$

write $(5,980)$

980 format(//,' best fit rate constants and reduced chi squared:')

write $(6,979)$ errorfinal

write $(5,979)$ errorfinal

do $41 \mathrm{i}=1$,nvar

write $(6,978) \mathrm{i}, \mathrm{x}(\mathrm{i})$

41 write $(5,978) \mathrm{i}, \mathrm{x}(\mathrm{i})$

978 format(' rate \#',i3,' = ',d20.8)

979 format(' error=',f20.8)

write $(3, *)(x(i), i=1$, nvar $)$

575 open(unit $=4$,name $=$ 'crk.dat',type $=$ 'new')

do $42 \mathrm{ja}=1, \mathrm{jb}$

C NEED TO GO TO integration SUBROUTINE TO CALC tt, zz, calc

C FOR EACH RUN, SINCE THESE WERE NOT STORED IN ARRAYS TO

C SAVE MEMORY WHEN PROGRAM WAS WRITTEN ORIGINALLY.

call integration(x)

write $(6,977) \mathrm{ja}$

write $(5,977) \mathrm{ja}$

977 format(///,', run \# ',i3,/)

if(ibi.eq.0) go to 43

do $44 \mathrm{i}=1, \mathrm{ibi}$

write $(6,976)$ i,biconc(i,ja)

44 write $(5,976)$ i,biconc(i,ja)

976 format(' concentration of bimolecular component \#',i2,' = ',

1 f 7.4 )

43 do $45 \mathrm{k}=2, \mathrm{id}+1$

if(k.gt.iobs+1) go to 46

if(output.ne.1) goto 573

write $(6,975) \mathrm{k}-1, \mathrm{k}-1$

write $(5,975) \mathrm{k}-1, \mathrm{k}-1$

975 format(/,' time species\#',i2,' obs species\#',

1 i2,' calc')

write $(6,974)(\operatorname{cobs}(1$, ja,ii),cobs(k,ja,ii),calc(k-1,ii),

$1 \mathrm{ii}=1, \mathrm{np}(\mathrm{ja}))$

write $(5,974)(\operatorname{cobs}(1, j a, i i), \operatorname{cobs}(k, j a, i i), c a l c(k-1, i i)$,

$1 \mathrm{ii}=1, \mathrm{np}(\mathrm{ja}))$

974 format(1h,f11.2,4x,e12.5,4x,e12.5)

go to 45

46 write $(6,973) \mathrm{k}-1$

write $(5,973) \mathrm{k}-1$

973 format( $/$, ' time unobserved species\#',i2,' calc') write $(6,972)(\operatorname{cobs}(1, \mathrm{ja}, \mathrm{ii}), \mathrm{calc}(\mathrm{k}-1, \mathrm{ii}), \mathrm{ii}=1, \mathrm{np}(\mathrm{ja}))$

write $(5,972)(\operatorname{cobs}(1, \mathrm{ja}, \mathrm{ii}), \mathrm{calc}(\mathrm{k}-1, \mathrm{ii}), \mathrm{ii}=1, \mathrm{np}(\mathrm{ja}))$

972 format(1h,f11.2,9x,e12.5)

45 continue 


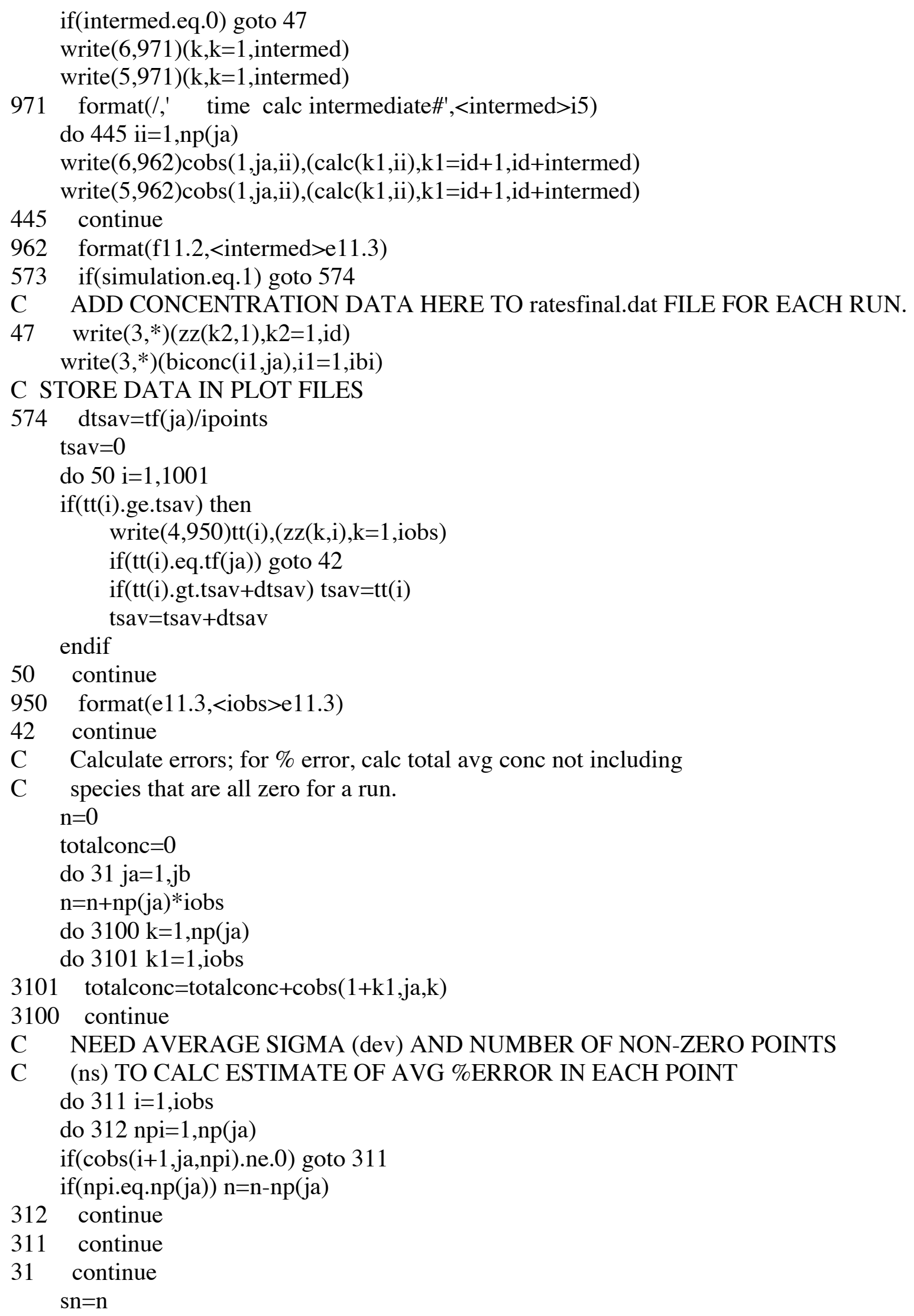




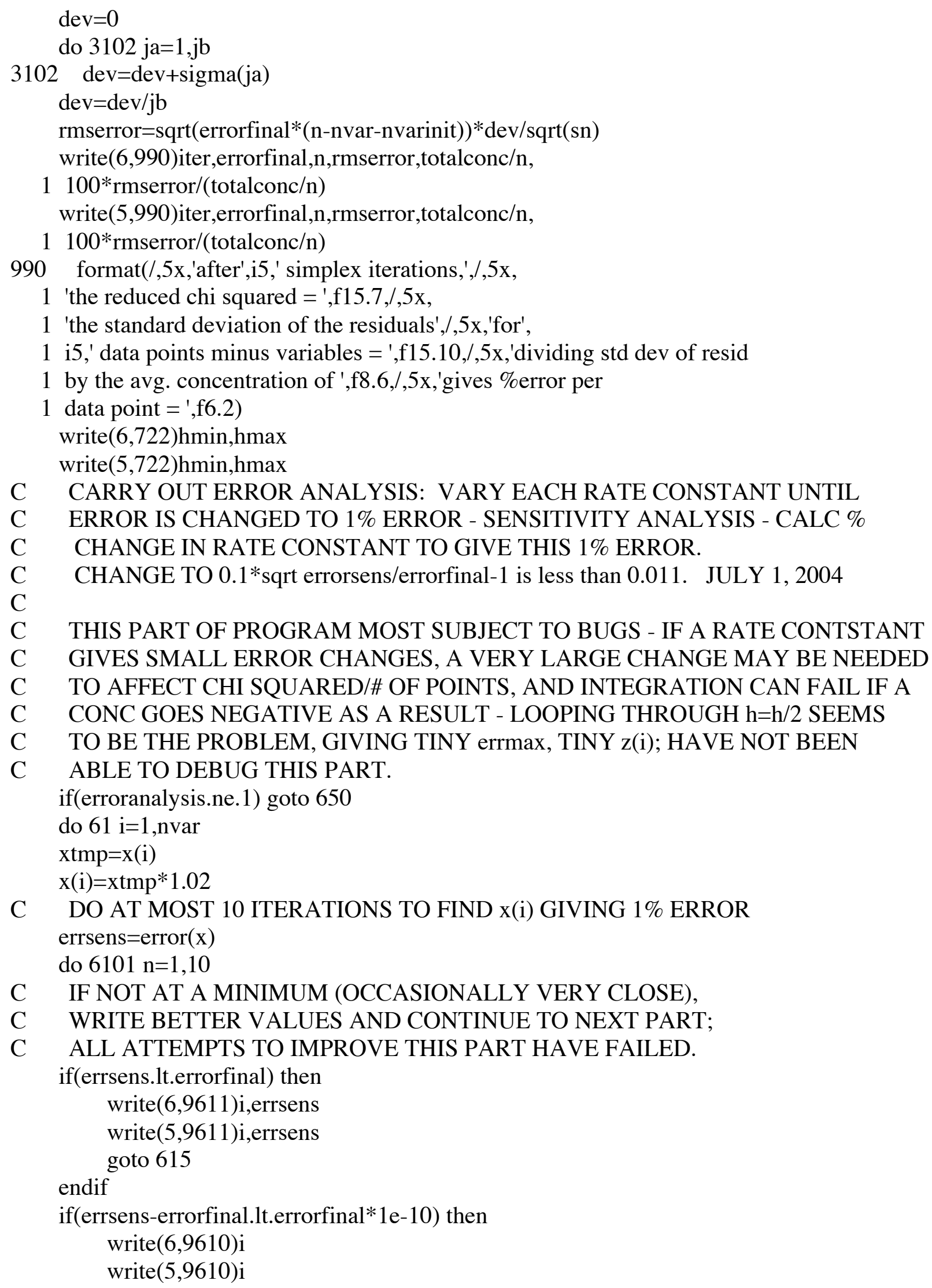




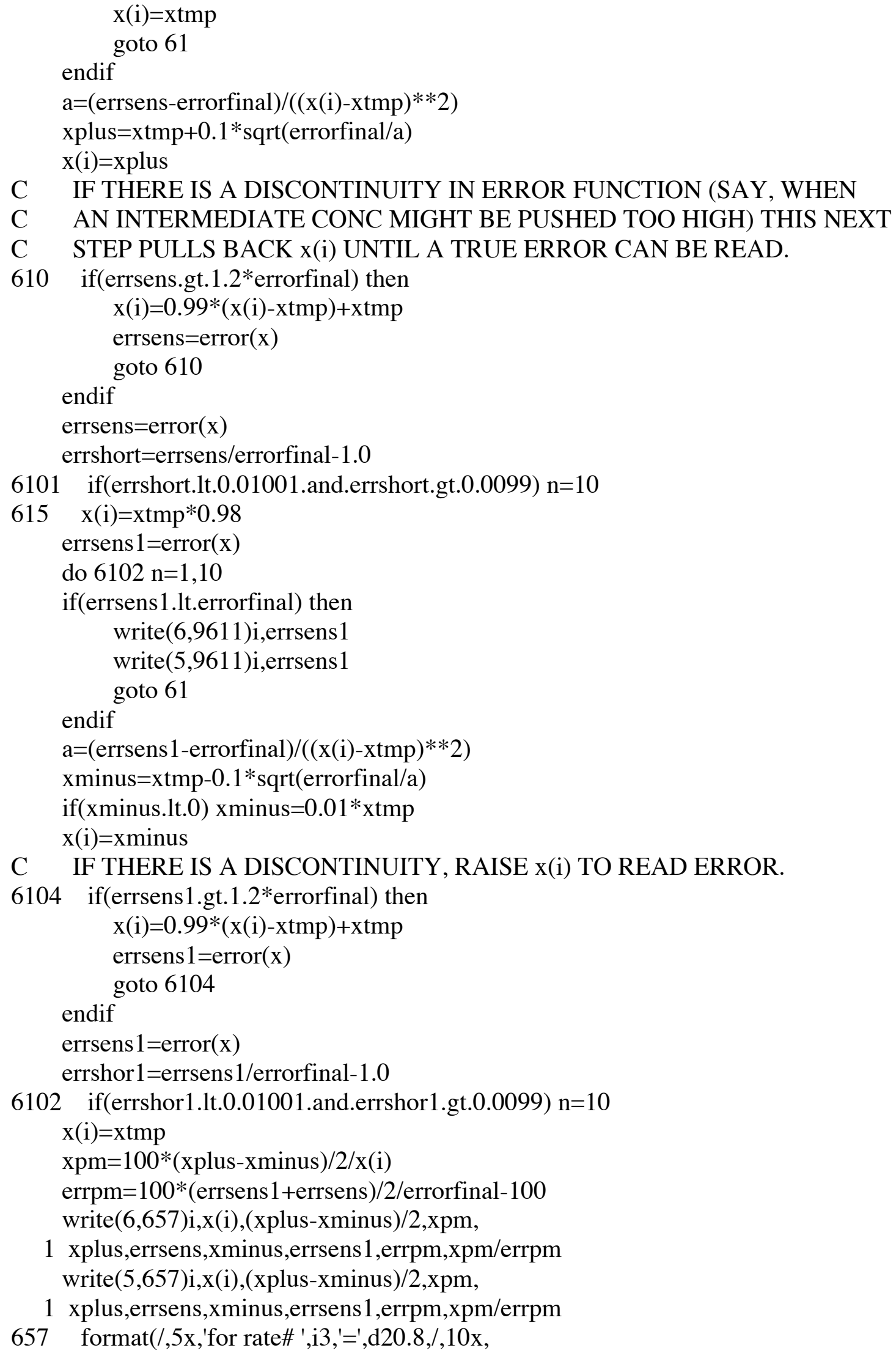


1 'the average deviation = ',d20.8,' for a $\%$ dev of ',f8.2,/,5x,

1 'xplus gives ',d20.8,' and err =

1 ',f20.8,/,5x,'xminus gives ',d20.8,' err = 'f20.8,/,5x,

1 'for an average $\%$ error of ',f8.2,/,5x,

1 'sensitivity analysis gives \% error in rc of ',f8.2,' for

$11.00 \%$ total error',/)

9610 format('You may have set rate \# ',i2,/,'equal to a

1 previous rate in the derivatives subroutine.',/,'This rate will be

1 skipped in the error calculation.')

9611 format('Rate \# ',i2,' gives a lower minimum of ',f20.8)

61 continue

650 continue

stop

end

$\mathrm{C}$

$\mathrm{C}$

$\mathrm{C}$

subroutine amoeba(p,y,mp,nps,ndim,ftol,error,iter)

implicit real*8(a-h,o-z)

parameter $(\mathrm{nmax}=30$, alpha $=1.0$, beta $=0.5$, gamma $=2.0$, itmax $=1000)$

dimension $\mathrm{p}(31,30), \mathrm{y}(31), \operatorname{pr}(\mathrm{nmax}), \operatorname{prr}(\mathrm{nmax}), \operatorname{pbar}(\mathrm{nmax})$

common/c/hstore,pc,pcintermed,eps,hmin,hmax,errmax,ipoints

mpts $=$ ndim +1

iter $=0$

write $(6,995)$ ftol $* 100$

write $(5,995) \mathrm{ftol} * 100$

995 format(//,1h,'terminate at',f10.6,' per cent',///)

1 ilo=1

if ((iter-25)/25*25.ne.iter-25) goto 500

write $(6,999)$ iter

write $(5,999)$ iter

999 format(' simplex iteration=',i3)

write $(6,998) \mathrm{y}(1)$

write $(5,998) y(1)$

998 format(' error for current rate constants =',f15.7)

write $(6,722) \mathrm{hmin}, \mathrm{hmax}$

write $(5,722) \mathrm{hmin}, \mathrm{hmax}$

722 format(' minimum and maximum step sizes used were ',

1 d8.2,' and ',f8.2,' seconds')

do $997 \mathrm{i}=1$,nps

write $(6,996) i, p(1, i)$

997 write $(5,996) \mathrm{i}, \mathrm{p}(1, \mathrm{i})$

996 format(' rate or conc \#',i2,' = ',d10.4)

500 if(y(1).gt.y(2))then 
[Insert remainder of subroutine amoeba exactly as in Numerical Recipies, substituting "error" for "FUNK," and ending with the two lines below; as noted at http://www.numericalrecipes.com/infotop.html\#distinfo, routines from Numerical Recipies cannot be distributed as source code.]

goto 1

end

$\mathrm{C}$

$\mathrm{C}$ function error(x)

C THIS ROUTINE CALCULATES ERROR=SUM OF OBS-CALC SQUARED

C FOR EACH EXPERIMENTAL POINT IN EACH KINETIC RUN

$\mathrm{C}$ To calc reduced chi square, which is what error(x) gives on output,

$\mathrm{C}$ divide by sigma squared for each run; statistically perfect fit

$\mathrm{C} \quad$ will be equal to number of points. Reduced chi square divides

$\mathrm{C}$ chi squared by degrees of freedom $=$ \# of points-\# of variables,

C so perfect fit gives a value of about 1 for all cases, if sigma is

$\mathrm{C}$ chosen properly. To flag a variable as not being changed, make sure

C to set its step size to zero, especially if in the program 2 variables

$\mathrm{C}$ are set equal to each other for convenience.

implicit real*8(a-h,o-z)

dimension $\mathrm{x}(30)$

common/a/dx(30), calc(30,30), biconc $(2,5)$,ja,jb,simulation

common/b/cobs(12,5,30),sigma(5),tf(5),ztzero(30,5),np(5)

common/c/hstore,pc,pcintermed,eps,hmin,hmax,errmax,ipoints

common/d/nvar,nvarinit,id,iobs,intermed

common/e/tt(1001),zz(30,1001), mapz(60)

error $=0$

C SUBTRACT OUT ZERO POINTS FOR ERROR CALC IF ALL=0

$\mathrm{C}$ This should have been done once in main and the value put in a common

C block, but it was done last.

$\mathrm{n}=0$

do $31 \mathrm{ja}=1$,jb

$\mathrm{n}=\mathrm{n}+\mathrm{np}(\mathrm{ja}) *$ iobs

do $311 \mathrm{i}=1$,iobs

do 312 npi=1,np(ja)

if(cobs(i+1,ja,npi).ne.0) goto 311

if(npi.eq.np(ja)) n=n-np(ja)

312 continue

311 continue

31 continue

C In next 2 loops, remove variable from subtraction if stepsize is zero.

do $3129 \mathrm{i}=1$,nvarinit*jb

3129 if $(d x(n v a r+i) . e q .0) n=n+1$

do $3128 \mathrm{i}=1$, nvar

3128 if(dx(i).eq.0) $n=n+1$ 


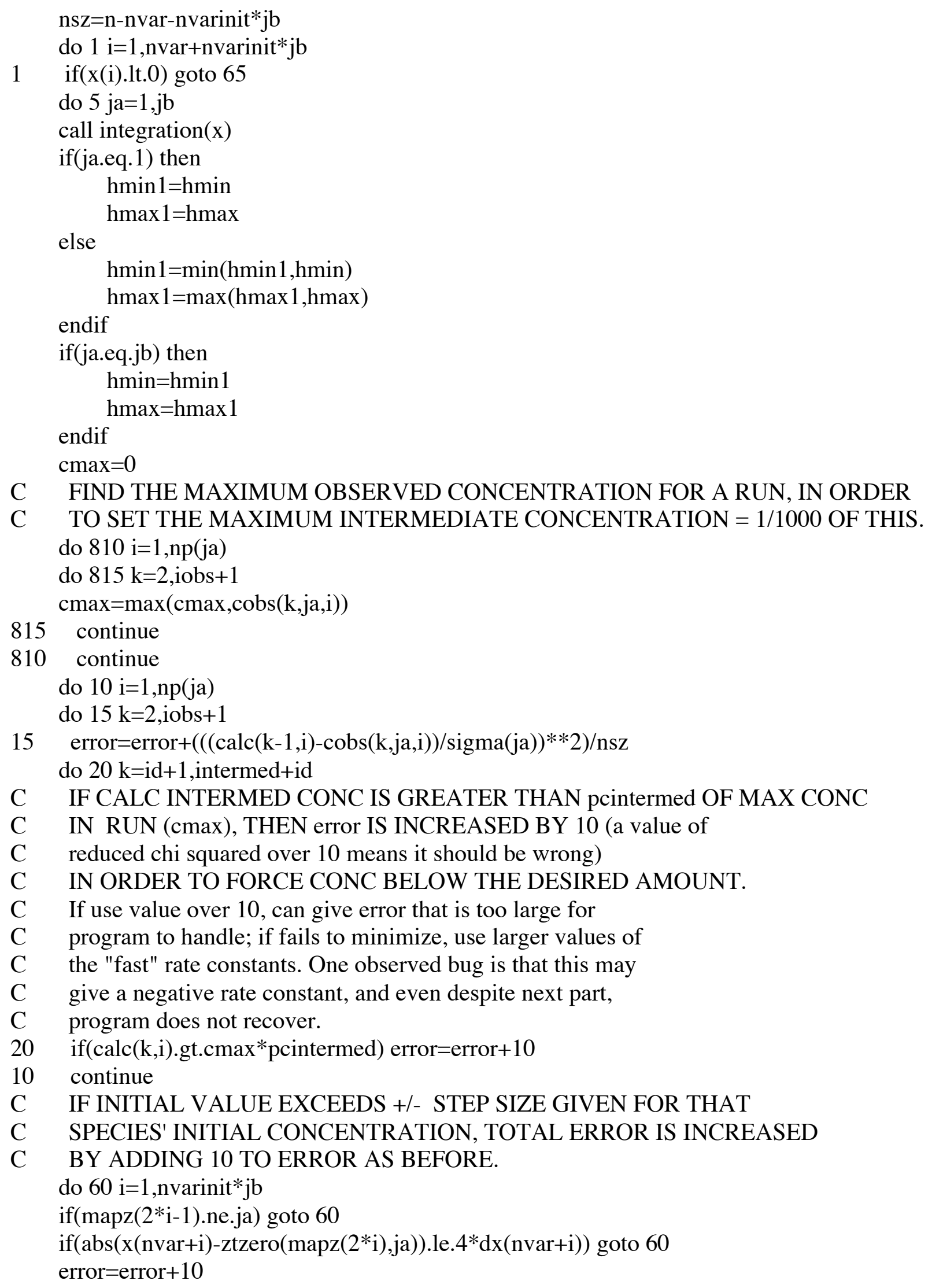




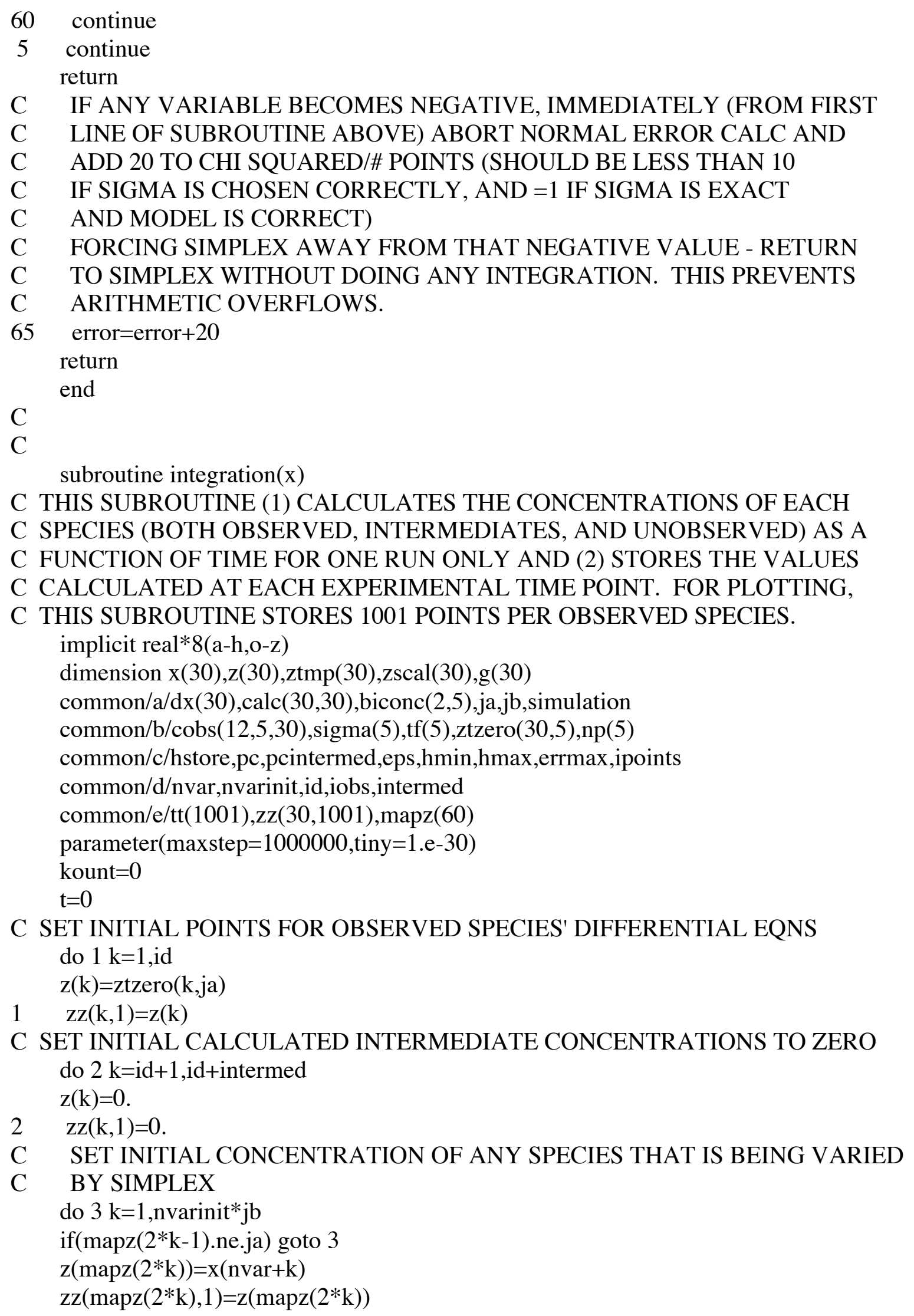


3 continue

C CHANGE 1000 IF YOU NEED MORE THAN 1001 POINTS FOR ACCURACY

$\mathrm{C}$ IN INTERPOLATION FOR CALC'D CONC'S AT OBSERVED TIMES

dtsav $=\mathrm{tf}(\mathrm{ja}) / 1000$

$\mathrm{h}=\mathrm{tf}(\mathrm{ja}) / \mathrm{hstore}$

$\mathrm{hmin}=\mathrm{h}$

C ASSURE STORAGE OF FIRST STEP

tsav $=\mathrm{t}-\mathrm{dtsav} * 2$.

C TAKE AT MOST maxstep STEPS

C IF YOU NOTICE THAT hmin IS SMALL AND INTEGRATION HAS

C NOT MADE IT TO THE LAST STEP, INCREASE MAXSTEP.

stepcount $=0$

do 16 nstep $=1$,maxstep

$\mathrm{hmin}=\min (\mathrm{h}, \mathrm{hmin})$

$\mathrm{hmax}=\max (\mathrm{h}, \mathrm{hmax})$

call deriv $(\mathrm{x}, \mathrm{t}, \mathrm{z}, \mathrm{g})$

call intermediates $(\mathrm{x}, \mathrm{z})$

C SCALING USED TO MONITOR ACCURACY. THIS GENERAL PURPOSE

C CHOICE CAN BE MODIFIED IF NEED BE.

do $12 \mathrm{i}=1$,id

$12 \quad$ zscal $(\mathrm{i})=\operatorname{abs}(\mathrm{z}(\mathrm{i}))+\mathrm{abs}(\mathrm{h} * \mathrm{~g}(\mathrm{i}))+$ tiny

C STORE INTERMEDIATE RESULTS.

if(t-tsav.gt.dtsav)then

kount=kount +1

$\mathrm{tt}($ kount $)=\mathrm{t}$

do $13 \mathrm{i}=1$,id+intermed

$13 \quad$ zz(i,kount $)=z(i)$

tsav $=\mathrm{t}$

endif

C IF LAST STEP CAN OVERSHOOT END, CUT DOWN STEPSIZE.

if $(t+h . g t . t f(j a)) h=t f(j a)-t$

call qcrunge(x,z,g,id,t,h,zscal,hdid,hnext)

call intermediates $(\mathrm{x}, \mathrm{z})$

C ARE WE DONE?

if $($ t.ge.tf(ja)) then do $14 \mathrm{i}=1$,id+intermed

$14 \quad \mathrm{ztmp}(\mathrm{i})=\mathrm{z}(\mathrm{i})$

C SAVE LAST STEP.

kount=kount +1

$\operatorname{tt}($ kount $)=\mathrm{t}$

do $15 \mathrm{i}=1$,id+intermed

$15 \quad z z(i, k o u n t)=z(i)$

goto 199

endif

if(hnext.lt.1e-4) stepcount=stepcount+1

$\mathrm{h}=\mathrm{hnext}$ 
16 continue

C LINEAR INTERPOLATION BETWEEN CALCULATED POINTS ON THE

C THEORETICAL LINES GIVES CALCULATED CONCENTRATION AT EACH

C EXPERIMENTAL TIME POINT FOR ALL SPECIES AND INTERMEDIATES

199 npoint $=1$

IF(STEPCOUNT.NE.0) THEN

write $(5,631)$ stepcount,errmax

write $(6,631)$ stepcount,errmax

return

ENDIF

do $200 \mathrm{i}=1$,kount

C CHECK WHEN INTEGRATED TIME EXCEEDS NEXT EXPERIMENTAL TIME IN

C OBSERVED DATA LIST

if(tt(i).1t.(cobs(1,ja,npoint)+tiny)) go to 200

$\mathrm{dt}=(\operatorname{cobs}(1, \mathrm{ja}$, npoint $)-\mathrm{tt}(\mathrm{i}-1)) /(\mathrm{tt}(\mathrm{i})-\mathrm{tt}(\mathrm{i}-1))$

do $41 \mathrm{k}=1$,id+intermed

$41 \quad$ calc $(\mathrm{k}, \mathrm{npoint})=\mathrm{zz}(\mathrm{k}, \mathrm{i}-1)+(\mathrm{zz}(\mathrm{k}, \mathrm{i})-\mathrm{zz}(\mathrm{k}, \mathrm{i}-1)) * \mathrm{dt}$

if(npoint.eq.np(ja)) goto 210

npoint $=$ npoint +1

200 continue

631 format(' got to $\mathrm{h}=.0001 \mathrm{sec}$ ',f10.0,' times, and errmax $=$ ',d11.5)

210 return

end

$\mathrm{C}$

$\mathrm{C}$

subroutine qcrunge(x,z,g,id,t,htry,zscal,hdid,hnext)

C THIS SUBROUTINE TAKES ONE QUALITY-CONTROLLED

C RUNGE-KUTTA STEP - 5TH ORDER WITH MONITORING OF

C LOCAL TRUNCATION ERROR TO ENSURE ACCURACY AND

C ADJUST STEPSIZE. INPUT ARE STEPSIZE htry TO BE

C ATTEMPTED, THE REQUIRED ACCURACY eps, AND THE

C VECTOR zscal AGAINST WHICH THE ERROR IS SCALED.

C ON OUTPUT, $\mathrm{z}$ AND $\mathrm{t}$ ARE REPLACED BY THEIR NEW

C VALUES, hdid IS THE STEPSIZE WHICH WAS ACTUALLY

C ACCOMPLISHED, AND hnext IS THE ESTIMATED NEXT

C STEPSIZE.

implicit real*8(a-h,o-z)

dimension z(30),g(30),zscal(30),ztemp(30),zsav(30),gsav(30)

common/a/dx(30),calc(30,30),biconc (2,5),ja,jb,simulation

common/b/cobs(12,5,30),sigma(5),tf(5),ztzero(30,5),np(5)

common/c/hstore,pc,pcintermed,eps,hmin,hmax,errmax,ipoints

parameter $($ pgrow $=-0.20$,pshrink $=-0.25$, fcor $=1 . / 15$., safety $=0.9$,

1 errcon=6.e-4)

C THE VALUE errcon $=(4 /$ safety $) * *(1 /$ pgrow $)$; SEE USE BELOW. tsav $=\mathrm{t}$ 
[Insert remainder of subroutine RKQC exactly as in Numerical Recipies, substituting variables in qcrunge(x,z,g,id,t,htry,zscal,hdid,hnext) for

RKQC(Y,DYDX,N,X,HTRY,EPS,YSCAL,HDID,HNEXT,DERIVS) in order, z=Y, $\mathrm{g}=\mathrm{DYDX}, . . . \mathrm{hnext}=\mathrm{HNEXT}$, and $\mathrm{x}$ is added to the array as shown, EPS is in common/c/ instead, and DERIVS is not included, and substituting deriv(x,t,z,g) for DERIVS(X,Y,DYDX) in the same way (i.e. $\mathrm{t}=\mathrm{X}, \mathrm{z}=\mathrm{Y}, \mathrm{g}=\mathrm{DYDX}$ ), and ending with the two lines below; as noted at http://www.numerical-recipes.com/infotop.html\#distinfo, routines from Numerical Recipies cannot be distributed as source code.]

return

end

$\mathrm{C}$

$\mathrm{C}$

subroutine rk4(x,z,g,id,t,h,zout)

C THIS SUBROUTINE PERFORMS 4TH ORDER RUNGE-KUTTA

$\mathrm{C}$ NUMERICAL INTEGRATION OF DERIVATIVES g IN SUBROUTINE

C deriv, STARTING AT TIME t AND CONTINUING OVER THE

$\mathrm{C}$ INTERVAL $\mathrm{h}$. OUTPUT DEPENDENT VARIABLES $\mathrm{z}$ IN ARRAY zout. implicit real*8(a-h,o-z)

dimension $\mathrm{z}(30), \mathrm{g}(30), \mathrm{zout}(30), \mathrm{zt}(30), \mathrm{gt}(30), \mathrm{gm}(30)$

$\mathrm{hh}=\mathrm{h} * 0.5$

[Insert remainder of subroutine RK4 exactly as in Numerical Recipies, substituting variables in rk4(x,z,g,id,t,h,zout) for RK4(Y,DYDX,N,X,H,YOUT,DERIVS) in order, z=Y,

$\mathrm{g}=\mathrm{DYDX}, \ldots \mathrm{zout}=\mathrm{YOUT}$, and $\mathrm{x}$ is added to the array as shown and DERIVS is not, and substituting deriv $(x, t, z, g)$ for DERIVS(X,Y,DYDX) in the same way (i.e. $t=X, z=Y, g=D Y D X)$, and ending with the two lines below; as noted at http://www.numerical-

recipes.com/infotop.html\#distinfo, routines from Numerical Recipies cannot be distributed as source code.]

return

end

$\mathrm{C}$

$\mathrm{C}$

subroutine deriv $(\mathrm{x}, \mathrm{t}, \mathrm{z}, \mathrm{g})$

C THIS SUBROUTINE CONTAINS THE SET OF DIFFERENTIAL

C EQUATIONS TO BE NUMERICALLY INTEGRATED, GIVEN

C THE STARTING CONDITIONS (TIME, CONC. OF EACH

C SPECIES), STARTING HERE AT LINE \#907

C Mech based on reversible formation of $\mathrm{MeCpMn}(\mathrm{CO}) 3$

$\mathrm{C}$ and mononuclear carbyne $\mathrm{CpFeC}-\mathrm{OMe}$, and one time

$\mathrm{C}$ exchange of carbyne with $2 \mathrm{bd} 3$ etc. in Scheme 6

C $\quad \mathrm{k} 1-\mathrm{k} 7=\mathrm{x}(1)-\mathrm{x}(7)$ and $\mathrm{f} 8=\mathrm{x}(8)$; Fix value of $\mathrm{x}(6)$ (one of the fast rc's).

C $g(1), z(1)$ are $1 \mathrm{a} ; \mathrm{z}(2) 1 \mathrm{bd} 3, \mathrm{z}(3) 2 \mathrm{a}, \mathrm{z}(4) 2 \mathrm{~b}, \mathrm{z}(5) 2 \mathrm{a}+2 \mathrm{ad} 3$,

C $z(6) 2 b+2 b d 3, z(7) \operatorname{MeCpMn}(C O) 3, z(8) 2 a d 3, z(9) 2 b d 3, z(10) \operatorname{PPh} 3$, 


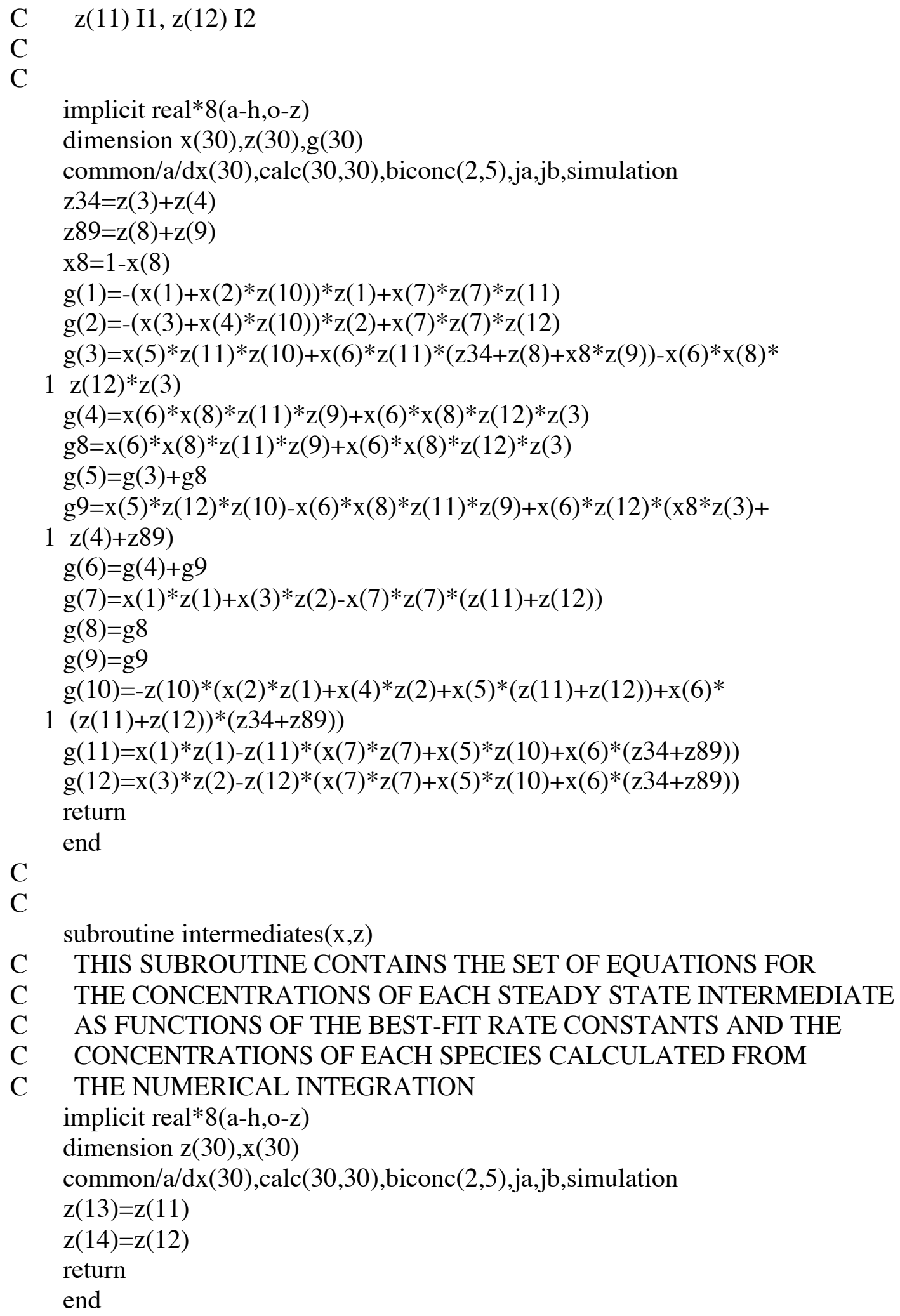




\section{Fortran subroutine for Scheme S-3}

subroutine deriv $(\mathrm{x}, \mathrm{t}, \mathrm{z}, \mathrm{g})$

C THIS SUBROUTINE CONTAINS THE SET OF DIFFERENTIAL

C EQUATIONS TO BE NUMERICALLY INTEGRATED, GIVEN

C THE STARTING CONDITIONS (TIME, CONC. OF EACH

C SPECIES), STARTING HERE AT LINE \#907

$\mathrm{C}$ Mech based on Scheme $\mathrm{S}-3$ circle mech using $\mathrm{CpFe}(\mathrm{CO}) \mathrm{Me}$ as

$\mathrm{C}$ both exchange intermediate and precursor to product;

C Rate constants are $\mathrm{x}(1)-\mathrm{x}(6) ; \mathrm{g}(1)$ is differential equation for $\mathrm{z}(1)$

C etc.; $z(1)=1 \mathrm{a}, \mathrm{z}(2)=1 \mathrm{a}-\mathrm{d} 3, \mathrm{z}(3)=2 \mathrm{a}, \mathrm{z}(4)=2 \mathrm{~b}, \mathrm{z}(5)=2 \mathrm{a}+2 \mathrm{a}-\mathrm{d} 3$,

C $z(6)=2 b+2 b-d 3, z(7)=\operatorname{MeCp}(C O) 3, z(8)=2 a-d 3, z(9)=2 b-d 3$,

C $\quad z(10)=P P h 3, z(11)=I a, z(12)=I b, z(13)=I a-d 3, z(14)=I b-d 3$

$\mathrm{C}$

implicit real*8(a-h,o-z)

dimension $\mathrm{x}(30), \mathrm{z}(30), \mathrm{g}(30)$

common/a/dx(30), calc(30,30), biconc(2,5),ja,jb,simulation

$\mathrm{z} 34=\mathrm{z}(3)+\mathrm{z}(4)$

$\mathrm{z} 56=\mathrm{z}(8)+\mathrm{z}(9)$

$\mathrm{z} 1011=\mathrm{z}(11)+\mathrm{z}(12)$

$\mathrm{z} 1213=\mathrm{z}(13)+\mathrm{z}(14)$

$\mathrm{x} 5=6 \mathrm{e}-5$

$\mathrm{g}(1)=-(\mathrm{x}(1)+\mathrm{x}(2) * \mathrm{z}(10)) * \mathrm{z}(1)$

$\mathrm{g}(2)=-(\mathrm{x}(3)+\mathrm{x}(4) * \mathrm{z}(10)) * \mathrm{z}(2)$

$\mathrm{g}(3)=(\mathrm{x}(5) * \mathrm{z}(10)+\mathrm{x}(6) * \mathrm{z}(8)) * \mathrm{z}(11)+\mathrm{x}(6) * \mathrm{z}(8) * \mathrm{z}(12)$

$\mathrm{g}(3)=\mathrm{g}(3)-\mathrm{x}(6) * \mathrm{z} 1213 * \mathrm{z}(3)-\mathrm{x} 5 * \mathrm{z}(3)$

$\mathrm{g}(4)=(\mathrm{x}(5) * \mathrm{z}(10)+\mathrm{x}(6) * \mathrm{z}(9)) * \mathrm{z}(12)+\mathrm{x}(6) * \mathrm{z}(9) * \mathrm{z}(11)$

$\mathrm{g}(4)=\mathrm{g}(4)-\mathrm{x}(6) * \mathrm{z} 1213 * \mathrm{z}(4)-\mathrm{x} 5 * \mathrm{z}(4)$

$\mathrm{g} 5=(\mathrm{x}(5) * \mathrm{z}(10)+\mathrm{x}(6) * \mathrm{z}(3)) * \mathrm{z}(13)+\mathrm{x}(6) * \mathrm{z}(3) * \mathrm{z}(14)-\mathrm{x}(6) * \mathrm{z} 1011 * \mathrm{z}(8)$

$\mathrm{g} 5=\mathrm{g} 5-\mathrm{x} 5 * \mathrm{z}(8)$

$\mathrm{g}(5)=\mathrm{g}(3)+\mathrm{g} 5$

$\mathrm{g} 6=(\mathrm{x}(5) * \mathrm{z}(10)+\mathrm{x}(6) * \mathrm{z}(4)) * \mathrm{z}(14)+\mathrm{x}(6) * \mathrm{z}(4) * \mathrm{z}(13)-\mathrm{x}(6) * \mathrm{z} 1011 * \mathrm{z}(9)$

$\mathrm{g} 6=\mathrm{g} 6-\mathrm{x} 5 * \mathrm{z}(9)$

$\mathrm{g}(6)=\mathrm{g}(4)+\mathrm{g} 6$

$\mathrm{g}(7)=\mathrm{x}(1) * \mathrm{z}(1)+\mathrm{x}(3) * \mathrm{z}(2)$

$\mathrm{g}(8)=\mathrm{g} 5$

$\mathrm{g}(9)=\mathrm{g} 6$

$\mathrm{g}(10)=-(\mathrm{x}(2) * \mathrm{z}(1)+\mathrm{x}(4) * \mathrm{z}(2)+\mathrm{x}(5) *(\mathrm{z} 1011+\mathrm{z} 1213)) * \mathrm{z}(10)$

$\mathrm{g}(10)=\mathrm{g}(10)+\mathrm{x} 5 *(\mathrm{z}(3)+\mathrm{z}(4)+\mathrm{z}(8)+\mathrm{z}(9))$

$\mathrm{g}(11)=\mathrm{x}(1) * \mathrm{z}(1)+\mathrm{x}(6) *(\mathrm{z} 34) * \mathrm{z}(13)-(\mathrm{x}(5) * \mathrm{z}(10)+\mathrm{x}(6) *(\mathrm{z} 56)) * \mathrm{z}(11)$

$\mathrm{g}(11)=\mathrm{g}(11)+\mathrm{x} 5^{*} \mathrm{z}(3)$

$\mathrm{g}(12)=\mathrm{x}(6) *(\mathrm{z} 34) * \mathrm{z}(14)-(\mathrm{x}(5) * \mathrm{z}(10)+\mathrm{x}(6) *(\mathrm{z} 56)) * \mathrm{z}(12)$

$\mathrm{g}(12)=\mathrm{g}(12)+\mathrm{x} 5 * \mathrm{z}(4)$

$\mathrm{g}(13)=\mathrm{x}(6) *(\mathrm{z} 56) * \mathrm{z}(11)-(\mathrm{x}(5) * \mathrm{z}(10)+\mathrm{x}(6) *(\mathrm{z} 34)) * \mathrm{z}(13)$ 


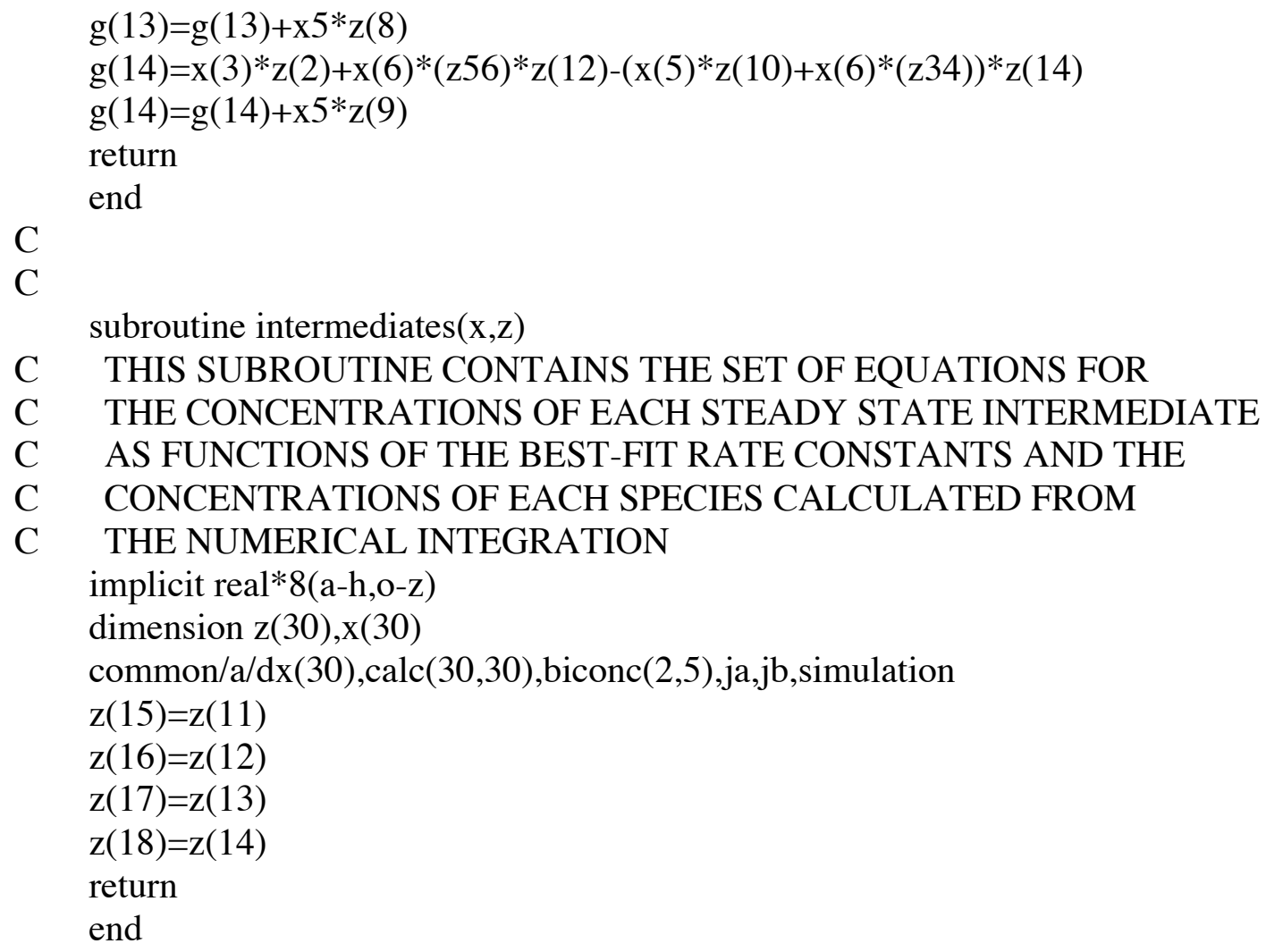

